NBER WORKING PAPER SERIES

\title{
IS THE CURE WORSE THAN THE DISEASE? UNINTENDED EFFECTS OF PAYMENT REFORM IN A QUANTITY-BASED TRANSFER PROGRAM
}

\author{
Katherine Meckel \\ Working Paper 26725 \\ http://www.nber.org/papers/w26725 \\ NATIONAL BUREAU OF ECONOMIC RESEARCH \\ 1050 Massachusetts Avenue \\ Cambridge, MA 02138 \\ January 2020
}

I thank Julie Cullen, Janet Currie, Wojciech Kopczuk, Ilyana Kuziemko, and Adriana LlerasMuney as well as seminar participants at APPAM, Columbia, Duke, the Federal Reserve Bank of Chicago, MSU, NBER Summer Institute, Notre Dame, Stanford, the STATA Texas Empirical Micro Conference, Texas A\&M, UCLA, UCSD, U Chicago - Booth, U Chicago - Harris and UIUC for helpful comments. I am grateful to Marc Montrose at the Texas Department of State Health Services (DSHS) for assistance with the births data, as well as Leona Duong, Ray Krzesniak, and MaryAlice Winfree at the Women, Infants and Children (WIC) Program at the Texas DSHS. Katherine Rittenhouse provided excellent research assistance. Researcher(s) own analyses calculated (or derived) based in part on data from The Nielsen Company (US), LLC and marketing databases provided through the Nielsen Datasets at the Kilts Center for Marketing Data Center at The University of Chicago Booth School of Business. The conclusions drawn from the Nielsen data are those of the researcher(s) and do not reflect the views of Nielsen, nor do they necessarily reflect the views of the National Bureau of Economic Research. Nielsen is not responsible for, had no role in, and was not involved in analyzing and preparing the results reported herein.

NBER working papers are circulated for discussion and comment purposes. They have not been peer-reviewed or been subject to the review by the NBER Board of Directors that accompanies official NBER publications.

(C) 2020 by Katherine Meckel. All rights reserved. Short sections of text, not to exceed two paragraphs, may be quoted without explicit permission provided that full credit, including ( $)$ notice, is given to the source. 
Is the Cure Worse than the Disease? Unintended Effects of Payment Reform in a Quantity-based Transfer Program

Katherine Meckel

NBER Working Paper No. 26725

January 2020

JEL No. H10,H53,I3

\begin{abstract}
Quantity vouchers are used in redistributive programs to shield participants from price variation and alter their consumption patterns. However, because participants are insensitive to prices, vendors of program goods are incentivized to price discriminate between program and nonprogram customers. I study these trade-offs in the context of a reform to reduce price discrimination in the Supplemental Nutrition Program for Women, Infants, and Children (WIC), which provides a quantity voucher for nutritious foods to low-income mothers and children. The reform caused vendors to drop out, reducing program take-up. In addition, smaller vendors increased prices charged to non-WIC shoppers by $6.4 \%$.
\end{abstract}

Katherine Meckel

Department of Economics

Econ 210

University of California at San Diego

9500 Gilman Drive \#0508

LaJolla, CA 92093

and NBER

kmeckel@ucsd.edu

An online appendix is available at http://www.nber.org/data-appendix/w26725 


\section{Introduction}

Many anti-poverty programs in the U.S. provide benefits in-kind, rather than in cash (Currie and Gahvari 2008; Hoynes and Schanzenbach 2015). Within in-kind programs, however, there is variation in the degree to which benefits are "cash-like." Some programs provide value vouchers, which operate as cash that can only be spent on certain goods. Other programs provide quantity vouchers, which confer fixed quantities.

As compared with value vouchers, quantity vouchers can be used to more effectively alter recipient consumption patterns and to hold the real value of benefits fixed, which is useful when local price variation is unobserved (Bronchetti, Christensen, and Hoynes 2018). However, when participants are shielded from price variation they become price-inelastic, incentivizing participating firms to increase their prices and raising the fiscal burden of the program. Despite these central economic trade-offs, there is relatively little evidence on the effectiveness of quantity vouchers in redistributive programs.

I examine these trade-offs by studying the effects of a payment reform in the Special Supplemental Nutrition Program for Women, Infants and Children (WIC) in Texas. WIC is a federal assistance program that provides low-income pregnant and breastfeeding women and children under the age of 5 with a monthly transfer of specific quantities of nutritious foods. Enrollees are issued quantity vouchers that can be redeemed at participating retail grocery stores ("WIC stores"). WIC is widely used, serving over $50 \%$ of infants in the U.S., and has been found to improve maternal and infant health (Bitler and Currie 2005; Figlio, Hamersma, and Roth 2009; Hoynes, Page, and Stevens 2011; Rossin-Slater 2013).

Prior to the payment reform, WIC participants used paper vouchers to purchase benefits. WIC stores would record the prices of benefits on the vouchers and then submit the vouchers for reimbursement. Because WIC customers are insensitive to prices, WIC stores are incentivized to charge them higher prices than they charge their non-WIC customers. Doing so was feasible prior to the reform because the technologies for charging WIC and non-WIC customers were completely separate (i.e., the paper voucher and the cash register, respectively). Price discrimination is prohibited by WIC program rules, but government reports find that it does occur, primarily among smaller stores (GAO 1999; Kamara, Castellanos-Brown, and Mantovani 2012; Saitone, Sexton, and Volpe 2015).

Under the reform, known as the Electronic Benefit Transfer (EBT), paper vouchers are replaced with a plastic smartcard that authorizes WIC transactions in the grocery checkout lane. EBT integrates the technology for charging WIC and non-WIC prices into the store's electronic cash register. In so doing, EBT enables the government to directly observe a store's prices, forcing them to charge a pooling price to WIC and non-WIC customers.

I model grocery stores as local monopolists who face fixed costs of participating in WIC due to requirements that they maintain a minimum stock of nutritious foods, for which demand is low in highpoverty areas (Waldfogel 2007; Bitler and Haider 2011; Allcott et al. 2018). From this model, I generate three predictions regarding the effects of EBT implementation. First, I predict that some stores will drop out of WIC after EBT is introduced. This reduction in WIC stores may lead to declines in benefit take-up among eligible households. Second, stores with higher fixed costs of participation (i.e., those in poorer areas) will be more likely to drop out. Third, stores that remain in WIC after EBT will increase 
the prices they charge non-WIC customers for WIC products (reflecting an increase from the separating price to the pooling price).

I then use these predictions to analyze the overall effect of EBT on social welfare. I find that the welfare effects of EBT are a priori ambiguous, and depend on the surplus associated with an additional household participating in WIC, the marginal excess burden, the level of the price-discrimination markup and the base over which the mark-up is applied. This finding emphasizes the importance of accounting for the cost of price discrimination in programs that provide quantity transfers. I also show that the only two parameters necessary to evaluate the welfare effect of EBT (or a similar price discrimination reform) are the marginal excess burden and the decrease in transactions that follows the reform.

Next, I empirically estimate the effects of EBT implementation on social welfare. To do so, I compile a novel dataset consisting of administrative records on WIC stores in Texas, transaction-level data on prices paid by non-WIC customers, and individual-level information on maternal WIC participation from the universe of birth certificates in Texas. Using the administrative data on WIC stores, I first establish the following: (1) independent WIC stores are more likely than chain WIC stores to serve high-poverty neighborhoods; (2) the likelihood of price discrimination is higher for independent WIC stores as well as stores in high-poverty areas; (3) access to WIC stores is limited in many areas of Texas.

To identify the causal effects of EBT, I estimate a difference-in-differences model that uses the staggered, county-level rollout of EBT in Texas to compare outcomes before and after EBT implementation while controlling for factors common to individual counties. For this identification strategy to be valid, it must be that EBT timing is uncorrelated with trends at the county level. I provide evidence in support of this assumption by demonstrating that the timing of EBT rollout is unrelated to numerous demographic and economic indicators at the county level.

Using administrative data on WIC stores, I first show that EBT reduces the number of independent WIC stores by $10.7 \%$. Effects for chain stores are small and statistically insignificant, corresponding to the fact that chains are less likely to price discriminate. Within the sample of chain WIC stores, however, the likelihood of dropout after EBT increases in local poverty. This finding implies that some of the difference in dropout behavior among chain and independent WIC stores is driven by differences in location.

I then use detailed data on prices at the store level to evaluate whether WIC stores charge higher prices to non-WIC customers for WIC products after EBT. I find that prices of WIC products in independent WIC stores increase after EBT by 6.4\%. The effect for chain WIC stores is small and insignificant, corresponding to the fact that they are less likely to price discriminate before EBT. I also estimate placebo tests using the subsamples of non-WIC products and non-WIC stores. Reassuringly, I do not find effects in these subsamples. Lastly, I show that stores which exit WIC after the introduction of EBT drop some of their WIC products, in line with the idea that these products are costly to carry in high poverty areas (where store dropout is concentrated).

To assess effects on benefit take-up, I use the sample of birth certificates to estimate whether EBT implementation reduces WIC participation among pregnant women. I find that participation among pregnant women decreases by $5.2 \%$ after EBT. Participation declines are proportionally larger among 
a subsample of high-poverty mothers, which corresponds to the fact that store dropout is concentrated in high-poverty ZIP codes.

Finally, I empirically estimate the overall effect of EBT implementation on social welfare. I first consider effects in the market that consists of WIC stores and WIC participants. I show that EBT implementation leads to a decrease in social welfare if the surplus that arises from an additional household participating in WIC is greater than $\$ 0.41$ per dollar of benefits. By way of comparison, the corresponding "break-even" value for a similar policy that restricts cash benefits by a dollar would only be \$0.30. This comparison emphasizes the fact that distributing transfers via quantity vouchers involves the additional cost of vendor mark-ups in response to price-inelastic participants.

Next, I additionally consider welfare effects in the market consisting of WIC stores and non-WIC customers. Adding in loss that arises in this market, the break-even cutoff for the surplus from an additional household participating in WIC falls to $\$ 0.33$. In this case, any value over $\$ 1$ implies a loss of at least 3.5\% of the pre-EBT value of program benefits. By comparison, outside estimates imply the surplus from an additional participant is at least $\$ 5.82$ per dollar of benefits.

I conclude by discussing policy alternatives. Reforms such as EBT may be essential for program viability in that they help maintain program integrity (Kuziemko et al. 2015). A welfare-improving program would therefore combine EBT with subsidies to increase vendor participation in underserved areas.

My findings can be extended to other redistributive programs that provide fixed quantities of goods or services. For example, housing assistance programs in the U.S. typically provide rental units with specific characteristics (e.g., number of rooms) for a fixed share of recipients' income. Units are often provided by private real estate owners, who decide whether or not to participate, submit reimbursement claims to the government, and serve both subsidized and unsubsidized clients. ${ }^{1}$ Collinson and Ganong (2018) find that landlords charge higher rental rates in response to the fact that housing assistance recipients are insensitive to prices. Additional evidence comes from the Medicaid program, under which beneficiaries pay subsidized prices for pharmaceutical drugs in prescribed quantities. Duggan and Scott Morton (2006) finds that pharmaceutical companies respond to price-insensitive participants by increasing their reimbursement prices. Other relevant programs include those that provide school meals and educational services to low-income households.2

The paper is organized as follows: Section 2 describes the institutional background; Section 3 formalizes incentives; Section 4 develops the social welfare model; Section 5 discusses the data; Section 6 presents the empirical method; Section 7 describes the empirical results; Section 8 estimates the overall social welfare impact; Section 9 concludes.

\footnotetext{
${ }^{1}$ Note that in some states, landlords are prohibited from price discriminating based on source of income.

${ }^{2}$ In addition, there is related work on quantity-based transfers in developing countries. Banerjee et al. (2019) study a program in Indonesia that provides households with a fixed transfer of rice and find that using a competitive bidding process to award distribution contracts lowers costs. Cunha, De Giorgi, and Jayachandran (2018) find that providing boxes of food to villages in Mexico lowers prices compared to cash transfers of equal monetary value.
} 


\section{Institutional Background}

WIC is a federal assistance program of the United States Department of Agriculture (USDA) whose aim is to ensure the nutritional well-being of low-income mothers and their young children. WIC participants are issued monthly vouchers that they exchange at participating grocery stores for specific types and quantities of nutritious foods. In addition to food, WIC provides participants with health screenings, nutrition classes, and referrals to other social services. WIC has been found to improve infant health, maternal health, breastfeeding, and access to other social services (Bitler and Currie 2005; Figlio, Hamersma, and Roth 2009; Hoynes, Page, and Stevens 2011; Rossin-Slater 2013).

WIC participants include pregnant and postpartum women, infants, and children under the age of 5. To be eligible, households must earn less than $185 \%$ of the Federal Poverty Level (currently, $\$ 47,638$ for a family of four) or qualify for Medicaid and be deemed "at nutritional risk," although the latter requirement rarely binds (IOM 2000; USDA-FNS 2019) $]^{3}$ In 2009, WIC served $51 \%$ of infants, $27 \%$ of children ages 1 to 4, and 29\% of pregnant and postpartum women nationwide (Martinez-Schiferl 2012).

Eligible households enroll at WIC clinics, of which there are about 2 to 3 per county in Texas (Rossin-Slater 2013). Although WIC is widely used, only about $60 \%$ of eligible households participate (Martinez-Schiferl, Zedlewski, and Giannarelli 2010). Research finds that distance to WIC clinics and documentation requirements are important barriers to enrollment (Bitler, Currie, and Scholz 2003; Swann 2007; Rossin-Slater 2013). These works are part of a broader literature on the determinants of take-up in public programs that emphasizes the importance of transaction costs and the role of providers (e.g., Currie and Fahr 2005; Currie 2006; Newhouse 2006; Aizer 2007; Kopczuk and Pop-Eleches 2007; Kuziemko, Meckel, and Rossin-Slater 2018).

Table 1 displays the standard monthly benefit packages for individuals enrolled in Texas WIC during the years of my study. The standard package for a pregnant woman is 5.5 gallons of milk, 6 juices, 2 dozen eggs, $2 \mathrm{lbs}$. of cheese, $36 \mathrm{oz}$. of adult cereal, and either a $1 \mathrm{lb}$. bag of dried beans or an $18 \mathrm{oz}$. jar of peanut butter. If she has children ages 1 to 4 , each child would entitle her to an additional: 4.5 gallons of milk, 4 juices, 2 dozen eggs, 2 lbs. of cheese, 36 oz. of adult cereal, and either a $1 \mathrm{lb}$. bag of dried beans or an $18 \mathrm{oz}$. jar of peanut butter. Modified packages are available in certain circumstances, such as when participants have food allergies or have limited access to refrigeration. In addition, quantities can be reduced if households are unable to use their full allotment 4

For each food type (e.g., "eggs"), WIC further restricts the set of products that can be purchased with WIC vouchers according to attributes like packaging size, flavor, etc. The rules defining product eligibility are jointly determined by the USDA and state WIC programs and meant to ensure nutritional content and limit costs (IOM 2006). Table A.1 displays the product eligibility rules for Texas WIC during the years of my study for the subset of foods I include in my analysis (eggs, peanut butter, beans, infant cereal, tuna, carrots, and infant formula) $!^{5}$

\footnotetext{
${ }^{3}$ Medicaid income eligibility thresholds, which are set at the state level, may be higher than $185 \%$ of the poverty level.

${ }^{4}$ Texas WIC policy reads "Tailoring the package to provide less than the full amount is appropriate when, for example...a participant refuses or cannot use the maximum monthly amount." Source: Procedure No. FD 12.0 (T), dated 12/2017, available here: https://www.dshs.texas.gov/wichd/policy/pdf_files/FD_12-0T.pdf.

${ }^{5}$ I compiled the product eligibility rules for FY 2007-2009 from archived versions of the Texas WIC website,
} 
Excluded from Table A.1, and my analysis below, are the following WIC food types: milk, juice, cheese, and cereal. For these foods, WIC imposes additional restrictions with respect to brand, and the eligible brand can vary across stores. ${ }^{6} \mathrm{I}$ do not observe these store-specific brand restrictions in my data on product eligibility rules and therefore cannot differentiate between eligible and ineligible products. Because my empirical strategy requires me to identify WIC-eligible products, I exclude these foods from my analysis. The foods that are included in my analysis cover about $30 \%$ of WIC package spending (USDA 2007).7

\subsection{Effects on Consumption and Pricing}

Rather than providing participants with quantity-based vouchers as described above, WIC could, for example, provide participants with vouchers worth a fixed value that operate like cash but are restricted to WIC-eligible products. In Section B, I demonstrate the effect of providing a quantity voucher versus a value-based voucher on a participant's budget set in the context of a program that provides two goods. Note that both vouchers are equivalent in monetary value. This exercise provides the following insight - quantity vouchers restrict participant choice relative to value-based vouchers because they impose a floor on the amount of each good that can be purchased.

Restricting participant choice may be welfare-improving if their unrestricted choices lead to loss (e.g., the case of a parent who buys too little nutritious food) 8 The trade-off highlighted in this article is that fixing quantities renders participants price-inelastic, which incentivizes vendors to raise their prices, potentially increasing the fiscal burden of such programs.

Correspondingly, previous research on WIC finds that it alters consumption patterns among participating households but also that there are important cost containment issues among vendors (Khan, Zhu, and Dhar 2018; Oliveira and Frazao 2009, respectively). Smaller WIC grocers are found to charge particularly high prices in response to price-inelastic WIC shoppers, as compared to chains (Saitone, Sexton, and Volpe 2015). In related work, McLaughlin, Saitone, and Sexton (2019) study a subset of

WIC stores that serve only WIC customers and find that their prices closely track the maximum allowed reimbursement rates 9

which I accessed using The Wayback Machine. The current list is here: https://www.dshs.texas.gov/wichd/vo/ TexasWICApprovedFoods.pdf.

${ }^{6}$ These regulations are known as "least expensive brand" rules, and, under these rules, stores must commit to distributing their least expensive brand, on average, per food product. Stores declare their least expensive brands at the start of each fiscal year (FY). For adult cereal, a list of around 30 specific UPCs are eligible each year, but I do not observe these UPC codes in the product eligibility rule lists.

${ }^{7}$ From Table 2, I add "Post Rebate Contribution" across eggs, infant cereal, beans, peanut butter, tuna, carrots, and infant formula, which sums to $26.7 \%$.

${ }^{8}$ Relatedly, the traditional rationale for providing transfers in-kind rather than in cash is that they can be used to alter consumption choices among recipients, as well as limit take-up by ineligible individuals (Nichols and Zeckhauser 1982 , Blackorby and Donaldson 1988; Besley and Coate 1992).

${ }^{9}$ Other research on vendors in the WIC program focuses the role of formula manufacturers (Oliveira and Davis 2006. Betson 2009; Oliveira, Frazao, and Smallwood 2010, 2011; Davis 2012, 2014, Huang and Perloff 2014). WIC procures rebates from formula manufacturers through competitive bidding - the winner becomes the WIC-eligible brand. 


\subsection{WIC Stores and Paper Vouchers in Texas}

In Texas, grocery stores can apply to participate in WIC at any time and applications are approved on a rolling basis. To be eligible, stores must carry a minimum inventory of WIC-eligible products. The inventory requirements include, for example, "at least 13.5 gallons of milk, some of which must be available in one-half gallon containers [including] whole milk and at least two of the following types of milk: low-fat, fat-free, and buttermilk" and "at least 6 dozen [eligible] eggs," and "at least 3 one-pound bags of [eligible] dry beans." "10 Taken together, these requirements disqualify an many convenience stores whose inventory is focused on shelf-stable goods and whose chilled storage is restricted to beverages.

Prior to the introduction of EBT, WIC participants purchased benefits using paper vouchers. Each voucher was usable for a 30 day period. Households were issued three months' worth of paper vouchers at a time during their trimonthly clinic appointments. Separate vouchers were issued to each participating member of a household. Perishable goods were also provided via separate vouchers, in order to prevent issues with spoilage. Figure A.3 shows an example of a voucher for a pregnant women issued by Texas WIC during the years of my study.

In the store, WIC participants gather their allotted quantities and bring them to the checkout line (a process that does not change with the introduction of EBT). In the checkout line, the WIC transaction would proceed as follows. First, the cashier would verify the eligibility of each product. Next, the cashier would write by hand the price of each good on the voucher in the blank space indicated. Then, the cashier would write on the voucher the name of the store and the date, and the participant would sign the voucher. Finally, the WIC store would mail the voucher to the state office for reimbursement. Note that no sales tax is applied to WIC purchases and no receipt is provided.

Paper vouchers (an example of which is shown in Figure A.3) display a "price not to exceed" next to each food item. These prices represent the maximum reimbursement rates WIC will pay stores per food product (both before and after EBT). Because vouchers can be used at any participating store, these price maximums must be set high enough to allow for price variation statewide as well as across different types of stores and are therefore unlikely to bind. The Texas WIC voucher is largely representative of vouchers used by other state programs 11

Because WIC participants receive the same quantities and types of foods regardless of price, they are insensitive to prices. Therefore, WIC stores may be able to increase profits by raising the price of WIC foods. In fact, if feasible, they will prefer to price discriminate between their WIC and non-WIC customers, charging the former a mark-up over the latter. The cost of doing so is the risk of incurring sanctions, as price discrimination in this form is prohibited by program regulations (at the federal level).

Alternatively, WIC stores could increase their payoff from participating by serving only WIC customers and charging exactly the maximum reimbursement rates. In Texas, WIC stores that serve only or

\footnotetext{
${ }^{10}$ Source: Texas DSHS, Policy WV.10, Dated Oct 1, 2007. Accessible here: https://web.archive.org/web/ 20071120193846/http://www.dshs.state.tx.us/wichd/vo/WV_10.0.pdf

${ }^{11}$ One difference is that some voucher states (e.g., CA) only require cashiers to enter the sum of prices of products distributed rather than the price per product. This lower level of required reporting would seem to further enable fraudulent price reporting, suggesting that my results may represent a lower bound with respect to the effects of EBT in other states.
} 
primarily WIC customers are called "WIC-only" and "Above 50" stores, respectively ${ }^{12}$ In 2004, Texas instituted new regulations tightly restricting the reimbursement rates paid to these types of stores. As a result, there are relatively few WIC-only and Above 50 stores during my sample period.

\subsection{Price Discrimination in WIC When Paper Vouchers Are Used}

Price discrimination between WIC and non-WIC customers is feasible when paper vouchers are used because the technologies for charging each type of customer are completely separate (i.e., paper voucher vs. cash register). The USDA refers to price discrimination as "overcharging," and provides the following definition: "Overcharging refers to a vendor charging the WIC customer more than a non-WIC customer would pay for the same item. It does not mean charging higher prices than other vendors" (Kamara, Castellanos-Brown, and Mantovani 2012).

Government reports confirm that overcharging does occur but find that it is concentrated among smaller stores, so budget impacts are likely limited. The USDA estimates that in FY 2009, 9.3\% of all WIC stores and $19.7 \%$ of small WIC stores overcharged (Kamara, Castellanos-Brown, and Mantovani 2012 ). Still, even when conducted on a small basis, fraud can threaten the viability of safety net programs through public outrage and political channels (Kuziemko et al. 2015).

To detect overcharging, state WIC agencies use undercover buys or audits to collect data on the prices paid by non-WIC customers and then compare them to prices written on paper vouchers on the same day in the same WIC store. Government reports suggest that these monitoring strategies are resource-intensive for state offices (GAO 1999). In addition, because WIC is fully federally funded, states have little incentive to reduce waste, particularly when faced with opposition from grocery lobbies (Oliveira and Frazao 2009). Consequently, all major cost-containment reforms to WIC have been at the federal level.

\subsection{Electronic Benefit Transfer (EBT)}

The transition from paper vouchers to EBT constitutes the latest federal cost-containment reform to the WIC Program. Under the Healthy, Hunger-Free Kids Act of 2010, all state WIC programs are required to implement EBT by Oct 1, 2020. EBT replaces paper vouchers with a plastic smartcard that stores a record of a WIC household's benefits and the dates between which the benefits can be redeemed.

Figure A.4 shows a picture of the EBT card issued by Texas WIC. EBT cards are reloaded with three months' worth of benefits at trimonthly clinic appointments (analogously to the issuance of paper vouchers before the introduction of EBT).

In order to accept EBT cards, WIC stores in Texas must have compatible electronic cash register (ECR) technology and install EBT software. At the start of EBT rollout, over $80 \%$ of existing WIC stores already had compatible ECRs and, therefore, did not need to acquire new machines. 13 Grocers that did need new ECRs were fully reimbursed for all installation and purchase costs and were also reimbursed for

\footnotetext{
${ }^{12}$ For "WIC-only" stores, WIC sales comprise $100 \%$ of food sales. "Above 50" WIC stores have WIC sales that comprise 50-99\% of their overall food sales. Source: https://hhs.texas.gov/sites/default/files/documents/ doing-business-with-hhs/provider-portal/wic/policy/wv-10-0.pdf.

${ }^{13}$ From an email to the author from Ray Krzesniak, who led the transition to WIC EBT In Texas: "These [EBTcompatible] ECR systems were used in more than $80 \%$ of all grocery stores in [Texas].
} 
monthly maintenance costs for three years. In addition, Texas directly facilitated purchasing, holding local expos around nine months before EBT rollout, during which grocers could "meet with [statecertified] software and ECR representatives, view and participate in product demonstrations, discuss store business and site installation needs, and, following selection of a WIC-enabled ECR product, negotiate purchase terms and conditions and an installation and conversion schedule." 14 Thus, significant effort was made to minimize transition costs for grocers.

With EBT technology, a WIC transaction proceeds as follows. The cashier first scans the barcode of each WIC product, generating a unique code known as a Universal Product Code (UPC). When a product is scanned, the ECR, which stores a correspondence between UPCs and prices at the store, assesses a price. After all items are scanned, the purchase is tendered with an EBT card, which triggers the following steps: (1) products are checked against a master list of eligible UPCs; (2) quantities are subtracted from the benefits stored on the card; and (3) the transaction record is flagged for upload to Texas WIC. Lastly, in place of a traditional receipt, the ECR prints a list of the household's remaining benefits in a format similar to the paper voucher.

Importantly, because prices are assessed before the transaction is tendered, WIC and non-WIC customers are charged the same price. By integrating the technology used to charge both types of customers (i.e., the ECR), EBT enables the government to directly observe a grocer's prices. Therefore, the store is forced to charge a single, pooling price to both WIC and non-WIC customers. Correspondingly, EBT is portrayed by government officials and analysts as a tool for mitigating overcharging (USDA 2006; NWA 2011; 2014).

Additional costs or benefits of EBT, outside of those due to the loss of price discrimination, are important to consider. For example, EBT may make it harder for stores to distribute ineligible products, as purchases are automatically compared against a list of WIC UPCs during checkout.15 It seems unlikely that WIC stores would be able to increase their profits by substituting lower cost products for WICeligible items, as the latter are generally chosen to be the lowest cost in their category. Participants may still wish to receive ineligible products that more closely align with their tastes. However, evidence suggests that participant fraud is rare (GAO 1999). Below, I provide direct evidence that participantinitiated fraud and substitution of ineligible products are rare in my setting.

Second, because WIC households now have more flexibility to partially redeem their benefits (e.g., purchasing only eggs on a given shopping trip and only milk on another trip), it may be that total quantity redeemed falls after EBT, which could reduce profits for stores, increasing dropout. Recall that a WIC participant's packages are reduced if they are not using the full benefit, making this scenario less likely. Third, EBT may reduce the costs for stores of getting reimbursed, as claims are now processed

\footnotetext{
${ }^{14}$ Source: Texas WIC "Tex Talks" Vendor Newsletter, October 17, 2005.

${ }^{15} \mathrm{In}$ fact, it is still technologically feasible for stores to sell ineligible products to WIC participants after EBT because the cashier can scan the barcode on one product but provide another to the WIC participant. Texas WIC currently lists this behavior as a sanctionable offense: "For using WIC allowable food scan codes from WIC food items, UPC codebooks, and/or UPC barcode/PLU reference sheets to provide an unauthorized food item and/or to provide an authorized WIC food item with a different UPC/PLU...The price difference between the amount charged to the SA and the WIC authorized item provided will not be paid....Three or more [instances] shall result in disqualification." Source: Policy No. WV:01.0, dated 8/2018, accessible here: https://www.dshs.texas.gov/wichd/policy/pdf_files/WV_01-0.pdf.
} 
electronically, rather than via mail. Below, I test the importance of additional costs and benefits of EBT for stores by estimating effects on participation among a group of vendors for which price discrimination is infeasible before EBT.

Finally, advocates for EBT argue that it reduces stigma (i.e. the psychological cost associated with receiving benefits) in the checkout line because the EBT card makes participants less identifiable. (Moffitt 1983). Manchester and Mumford (2010) compare the effects of time costs and stigma on the take-up of WIC and SNAP benefits, and conclude that stigma is the more important cost. However, Currie and Grogger (2001) do not find evidence that replacing paper vouchers with EBT cards reduced stigma in the SNAP program. If EBT reduces stigma, then my estimates of the negative effects of EBT on participation among pregnant women would be attenuated ${ }^{16}$

\section{Formalizing Incentives}

In this section, I formalize incentives for grocery stores participating in the WIC Program, and generate three predictions regarding the impacts of the introduction of EBT. I model grocers as monopolists, following evidence that shoppers are locally constrained by travel costs and perishable goods (e.g Ellickson 2006; Ellickson and Grieco 2013; Ellickson, Houghton, and Timmins 2013) and that low-income neighborhoods have limited access to fresh grocers and retail chains (e.g., Powell et al. 2007; Bitler and Haider 2011; Rimkus et al. 2015; Allcott et al. 2018). Below, I discuss the effects of relaxing the assumption that grocers are monopolists on my predictions.

Consider a grocery store that does not participate in WIC. Suppose for simplicity that the store sells a single, WIC-eligible product. The store sets price $p$ and faces customer demand of $q(p)$, where $q^{\prime}(p)<0$. Then, profits for this store are given by $\pi=(p-c) q(p)$, where $c$ is a constant representing marginal cost. ${ }^{17}$ Define $p^{*}$ as the profit maximizing price and $q\left(p^{*}\right)$ as equilibrium demand.

I make two additional assumptions that simplify the model. First, I assume that a store's WICeligible shoppers only participate in WIC if their local store does. Second, I assume that a store's WIC shoppers only purchase WIC products when using WIC vouchers (i.e., not out of pocket). Then, $q(p)$ represents demand by non-WIC customers only. I discuss the implications of relaxing these assumptions below.

Now, consider a grocery store that participates in WIC prior to the introduction of EBT. The store sets two prices for the same good - v, the price written on the vouchers and charged to WIC customers and $p$, the price charged to non-WIC customers. The store sells $q(p)$ to its non-WIC customers and distributes $b$ benefits to its WIC customers. Note that $b$ is a constant, set by WIC program eligibility rules and unaffected by prices. Price discrimination in this model occurs when $v>p$.

Let $\gamma$ denote the fixed costs for stores of participating in WIC. I hypothesize that these fixed costs are associated with the requirements to maintain a minimum stock of fresh and healthy foods, for which

\footnotetext{
${ }^{16}$ In related work, Hanks et al. (2019) use data on transactions linked to loyalty cards from a chain in Ohio and find that WIC expenditures increase after EBT. EBT technology in Ohio likely increases the use of loyalty cards in the processing of WIC transactions. These results are also consistent with a switch toward chain WIC stores after smaller stores drop out.

17 Stroebel and Vavra (2019) provide empirical evidence that marginal costs are constant for grocery stores.
} 
demand is low in high-poverty areas (Waldfogel 2007; Allcott et al. 2018) ${ }^{18}$ Let $\mu$ denote program sanctions for price discrimination, expressed as a rate per benefits $b$. Store profits are then given as follows, where the superscript $w 0$ indicates that store participates in $\mathrm{WIC}(w)$ in the time period before EBT is rolled out (0):

$$
\pi^{w 0}=(v-c-\mu) b-\gamma+(p-c) q(p)
$$

I assign the following functional form to sanctions: $\mu=\theta(v)(v-p) . \theta(v)$ is the likelihood that stores are investigated, and $(v-p)$ is the amount of the sanction conditional on investigation. This format - probability of apprehension times sanction if apprehended - follows the canonical crime penalty function from Becker (1968). I assume $\theta^{\prime}(v)>0$ and $\theta^{\prime \prime}(v)>0.19$

The sanction function follows directly from Texas WIC policy. WIC officials decide which stores to investigate based on the submitted voucher prices $v$ - for example, they may look for voucher prices that are unusually high. If an investigation is initiated, a WIC employee performs an "undercover buy," during which time she poses as a WIC client and completes a WIC transaction with a marked voucher. She also covertly records the posted prices $(p)$ for the WIC items she receives. WIC officials then compare the recorded prices $(p)$ to the prices written on the marked voucher $(v)$ and submitted by the store for reimbursement. If price discrimination is found $(v>p)$, the store must pay back amount of the price discrimination, $v-p$ (and no more) 20

Define $p^{*}=\arg \max \pi$ and $\left(\bar{p}^{*}, v^{*}\right)=\arg \max \pi^{w 0} \cdot p^{*}$ is differentiated from $\bar{p}^{*}$ because the WIC penalty is decreasing in $p$, so $p^{*} \leq \bar{p}^{*}$, all else equal. Then, prior to the introduction of EBT, stores will participate in WIC if:

$$
\pi^{w 0}\left(\bar{p}^{*}, v^{*}\right) \geq \pi\left(p^{*}\right)
$$

Recall that I assume that when a store drops out of WIC all of its WIC customers leave the program. Suppose there are $S$ stores, indexed by $s$. Then, total benefits distributed, $B$, equals the sum of benefits, $b$, distributed by stores that participate.

$$
B=b \sum_{S} \mathbf{1}\left(\pi_{s}^{w 0}\left(\bar{p}^{*}, v^{*}\right)>\pi_{s}\left(p^{*}\right)\right)
$$

Now suppose EBT is introduced. WIC stores can no longer price discriminate $(v=p)$, as they are forced to use the same technology to transact WIC and non-WIC purchases. Profits are now given as follows, where the superscript $w 1$ now indicates that the store participates in WIC $(w)$ in the time

\footnotetext{
${ }^{18}$ Following (Waldfogel 2007), if there are fixed costs of stocking a given product (e.g., opportunity cost of shelf space, or the purchase of a refrigerator for fresh storage), then local retailers will stock items that reflect the tastes of the majority of their consumers.

${ }^{19}$ To specify $\theta$ as a true likelihood (i.e., always between 0 and 1 ) a logistic function could be used, which is convex for some values of $v$, in place of a convex function. The main point is that $\theta$ is convex in the relative range of $v$.

${ }^{20}$ Since stores are only penalized by the amount of the price discrimination, all stores should price discriminate, as the expected value of doing so is always positive $((v-p)>\mu(v-p)$, since $0<\mu<1$ by assumption). However, there may be additional fixed costs of being caught (e.g., loss of reputation, the hassle of being investigated) that prevent some stores from price discriminating. Source: Texas WIC Policy WV 01.0, dated 8/2016
} 
period after EBT is introduced (1).

$$
\pi^{w 1}=(p-c)(b+q(p))-\gamma
$$

Define $\hat{p}^{*}=\arg \max \pi^{w 1}$. Note that $\pi^{w 1}$ is in fact a constrained version of $\pi^{w 0}$ — if we set $v=p$ in $\pi^{w 0}$, the expression reduces to $\pi^{w 1}$ because $\mu(v=p)=0$. Therefore, it must be that $\pi^{w 1}\left(\hat{p}^{*}\right) \leq \pi^{w 0}\left(\bar{p}^{*}, v^{*}\right)$, as a constrained maximum is necessarily less than or equal to the unconstrained maximum. Conceptually, EBT reduces the rent stores used to get from price discrimination. My model therefore generates the following predictions.

Prediction 1. Some stores will drop out of WIC after the introduction of EBT

Because a store's customers only participate in WIC if the store does, the reduction in WIC stores will reduce benefit take-up. The new, lower level of benefits after EBT is given as follows.

$$
B=b \sum_{S} \mathbf{1}\left(\pi_{s}^{w 1}\left(\hat{p}^{*}\right)>\pi_{s}\left(p^{*}\right)\right)
$$

Suppose there is heterogeneity across stores $s$ in the fixed costs of participating in WIC, $\gamma_{s}$. Then:

Prediction 2. Stores with higher fixed costs of participating in WIC will be more likely to drop out after the introduction of EBT.

What about the WIC share of customers, $\frac{b}{b+q}$ ? If stores with a higher share of WIC customers are more likely to drop out after EBT is introduced and have higher $\gamma_{s}$, then perhaps the WIC share drives any observed correlation between $\gamma_{s}$ and store drop out. Section C provides a short proof that, within this model, stores with a higher share of WIC customers, all else equal, should be less likely to drop out after EBT. The intuition is that those stores can charge a higher price ex-ante since they have a higher share of inelastic WIC customers.

My third prediction concerns prices in stores that remain in WIC after EBT is introduced.

Prediction 3. For sufficiently bounded $\theta$ and $\theta^{\prime}$, the price paid by non-WIC customers in WIC stores increases once EBT is introduced: $\hat{p}^{*}>\bar{p}^{*}$.

Conceptually, the EBT price $\hat{p}^{*}$ reflects pooled WIC (inelastic) and non-WIC (elastic) demand and therefore should lie somewhere in the middle of the separating prices charged pre-EBT $\left(\bar{p}^{*}<\hat{p}^{*}<v^{*}\right){ }^{21}$ Section $\mathrm{D}$ provides short proofs for the predictions above.

Next, I discuss the implications of relaxing the assumptions made above. First, relaxing the assumption that grocers are monopolists to allow for a limited form of competition does not change the sign of my predictions, only the magnitude. If WIC stores face competition, they will increase prices after EBT by a lower amount because non-WIC demand is more elastic. As for the prediction that stores will drop out of WIC after EBT, the magnitude of this effect would increase (i.e., more store dropout), because

\footnotetext{
${ }^{21}$ Some upper bounds on $\theta\left(\hat{p}^{*}\right)$ and $\theta^{\prime}\left(\hat{p}^{*}\right)$ are necessary to to guarantee that stores set $v^{*}$ above $\hat{p}^{*}$. Conceptually, if sanctions are high at $\hat{p}^{*}$, stores will not increase $v$ above $\hat{p}^{*}$.
} 
the lower pooling price reduces the profitability of participating in WIC. If non-WIC customers are able to substitute towards non-WIC items or non-WIC stores to avoid the price increases after EBT, there should be price increases in these subsets. Fortunately, my data enable me to test for these effects. I also provide evidence on market density in areas where WIC stores are located.

A related assumption is that eligible households only participate in WIC if their local store does. If, instead, WIC participants stay enrolled after their local store exits, they would shift their WIC purchases to other WIC stores nearby. In this case, these stores may increase their prices after EBT because they would have more price inelastic customers. However, such effects should show up in both independent and chain WIC stores. Such effects are likely small because there are few grocery stores in the areas where WIC store exit is concentrated, as I discuss below.

A third assumption made above is that WIC-eligible customers only buy WIC products while participate in WIC. Suppose, instead, that a WIC eligible households starts purchasing WIC products out-of-pocket at their local store after it drops out of WIC. In this case, the prices of WIC products in WIC stores that drop out after EBT should increase. I am also able to test this prediction with my data 22

\section{Social Welfare}

I now use my predictions to account for the overall effect of EBT introduction on social welfare. First, consider the market for WIC benefits, shown in Figure 1. Before the rollout of EBT, WIC reimburses stores $v^{*} B$ for distributing benefits, resulting in store profits of $\left(v^{*}-c\right) B$. The demand curve shown represents society's willingness to pay for an additional household to participate in WIC. Note, importantly, that the demand curve is not necessarily that of the WIC participant and may, in fact, lie above hers if she does not fully internalize the value of nutritious foods and health services - indeed, this scenario is one of the key justifications for the WIC program. Additionally, society's demand curve may not slope downward (as pictured), as marginal households may benefit relatively more from participating. In my welfare calculations below, I assume a flat demand curve for simplicity.

After EBT is introduced, some stores drop out of WIC, reducing access to benefits and take-up among eligible households. Let $-\Delta B$ denote the resulting decrease in benefits, so $-\Delta B=B\left(\hat{p}^{*}\right)-B\left(\bar{p}^{*}, v^{*}\right){ }^{23}$ For stores that stay in WIC after EBT, the reimbursement rate falls from $v^{*}$ to $\hat{p}^{*}$.

Figure 1(c) displays the corresponding changes to consumer and producer welfare (where consumers and producers are society and WIC stores, respectively). The area labeled $\boldsymbol{A}$ is the transfer from WIC stores to the government due to the reduction in reimbursement rates. Then, $\boldsymbol{A}=\left(v^{*}-\hat{p}^{*}\right) B\left(\hat{p}^{*}\right)$. The combined area $\boldsymbol{B}+\boldsymbol{C}$ is the loss that arises as a result of fewer benefits being distributed after EBT. $\boldsymbol{B}+\boldsymbol{C}$ equals $\boldsymbol{B}+\boldsymbol{C}+\boldsymbol{D}$, the loss in consumer surplus, plus $\boldsymbol{C}$, the loss in producer profits, net of $\boldsymbol{C}+\boldsymbol{D}$, the transfer from WIC stores to the WIC program. Let $\alpha$ denote the increase in consumer and producer surplus associated with an additional household participating in WIC, which I assume is fixed

\footnotetext{
${ }^{22}$ Another, related, assumption implied in the setup above is that WIC customers do not purchase WIC products out of pocket while they participate in WIC. Relaxing the assumption would imply that $q(p)$ reflects a mix of non-WIC demand and price sensitive (out of pocket) WIC demand. In this case, my predictions would remain the same.

${ }^{23}$ I define $\Delta B$ to be a positive quantity to simplify the notation below.
} 
for simplicity, so that $(\boldsymbol{B}+\boldsymbol{C})=\alpha(\Delta B) 24$

An additional element of the change in welfare due to EBT, not shown on Figure 1, is the increase in government surplus that arises due to the lower level of spending on WIC benefits. Let $\lambda$ denote the marginal excess burden of raising funds, so the increase in government surplus is $\lambda(\boldsymbol{C}+\boldsymbol{D})=\lambda v^{*}(\Delta B)$. Then, the overall change in social welfare is given by:

$$
\begin{aligned}
\Delta \text { Social Welfare }= & \lambda \text { Gov't Savings from Lower Mark-Up } \\
& +\lambda \text { Gov't Savings from Reduction in Benefits } \\
& - \text { Loss in Surplus from Fewer Benefits } \\
= & \lambda(\boldsymbol{A})+\lambda(\boldsymbol{C}+\boldsymbol{D})-(\boldsymbol{B}+\boldsymbol{C}) \\
= & \lambda\left(v^{*}-\hat{p}^{*}\right) B\left(\hat{p}^{*}\right)+\lambda v^{*}(\Delta B)-\alpha(\Delta B) \\
= & \left(\lambda v^{*}-\alpha\right)(\Delta B)+\lambda\left(v^{*}-\hat{p}^{*}\right) B\left(\hat{p}^{*}\right)
\end{aligned}
$$

The first term, $\left(\lambda v^{*}-\alpha\right)(\Delta B)=\left(\alpha-\lambda v^{*}\right)(-\Delta B)$, is the savings associated with the reduction in benefits after EBT. The term $\alpha-\lambda v^{*}$ represents the welfare gain to society of transferring an additional benefit minus the efficiency cost. Note, importantly, that the welfare gain of providing an additional cash transfer of equivalent dollar value to the participant is $\alpha-\lambda p^{*}$, where $p^{*}$ denotes the price charged by stores that do not participate in WIC. Therefore, it must be that the benefits of providing transfers in-kind (e.g., via paternalism or other mechanisms) outweigh the extra cost of vendor mark-ups $\left(v^{*}-p^{*}\right)$ that occur when quantity vouchers are used.

The second term, $\lambda\left(v^{*}-\hat{p}^{*}\right) B\left(\hat{p}^{*}\right)$, represents the savings (voucher price minus EBT price) associated with the reduction in reimbursement rates in stores that remain in WIC after EBT. Therefore, Eq. 1 provides the following insight - even if the marginal excess burden is small relative to the welfare gain $\left(\alpha-\lambda v^{*}>0\right)$, the reduction in participation associated with the introduction of EBT may be worth it if either (1) the base over which price discrimination occurs $\left(B\left(\hat{p}^{*}\right)\right)$ is large relative to the decline in participation $(\Delta B)$ or $(2)$ the mark up $\left(v^{*}-\hat{p}^{*}\right)$ is large (or both). This point underscores the importance of accounting for the role of vendors when evaluating quantity-based transfer programs.

Further, there may be additional welfare loss associated with EBT if WIC has equilibrium effects in the private market for program goods. In general, in-kind transfers can aggravate deadweight loss that occurs in a market that is imperfectly competitive. In a competitive economy where vendors are price takers, changes to equilibrium price or quantity caused by in-kind transfers would operate as pecuniary

\footnotetext{
${ }^{24}$ Here, I am abstracting away from the issue of welfare weights (i.e., assuming a participant welfare weight of 1). In fact, the change in social welfare is the product of the change in surplus and the welfare weight assigned by the government. It is possible, however, to re-define $\alpha$ as the product of surplus, $\bar{\alpha}$, and the welfare weight, $\omega$, such that $\omega(\boldsymbol{B}+\boldsymbol{C})=\omega \bar{\alpha}(\Delta B)=\alpha(\Delta B)$. Still, I do not allow for differing welfare weights for non-WIC participants, store owners or high income households (who are taxed), as estimating these weights is outside the scope of the article. However, it is possible that store owner welfare weights are important, for example, in states with large grocery lobbies. Then, the loss in profits associated with EBT would result in further welfare loss.
} 
effects, changing the distribution but not the sum of social welfare. However, if vendors have market power, as in the case of the grocery market, a reform that affects their pricing behavior can change the sum of deadweight loss. Therefore, a generalized version of the change in social welfare should note the dependence of the additional terms below on market structure.

Figure A.1 shows the market consisting of a price-discriminating WIC grocery store and its non-WIC customers. Before EBT, as shown in Figure A.1(a), the equilibrium price is the separating price, $\bar{p}^{*}$. After EBT, the WIC store can no longer price discriminate, and it increases the non-WIC price to the pooling price $\hat{p}^{*}$ (Figure A.1(b)). As a result, the number of trades decreases and producer and consumer surplus decrease - the change is $\boldsymbol{F}$ and $\boldsymbol{G}$ in Figure A.1(c), respectively.

If we assume non-WIC consumer demand is linear in prices, for simplicity (as shown in Figure A.1), then $\boldsymbol{F}$ can be written as the area of a triangle: $0.5\left(\hat{p}^{*}-\bar{p}^{*}\right)\left(q\left(\bar{p}^{*}\right)-q\left(\hat{p}^{*}\right)\right)$. Similarly, $\boldsymbol{C}$ can be written as $\left(\bar{p}^{*}-c\right)\left(q\left(\bar{p}^{*}\right)-q\left(\hat{p}^{*}\right)\right)$, where $c$ is marginal cost, as above. Let $\epsilon_{p}$ denote the price elasticity of demand, such that $\epsilon_{p}=\frac{q\left(\hat{p}^{*}\right)-q\left(\bar{p}^{*}\right)}{\hat{p}^{*}-\bar{p}^{*}} \frac{\bar{p}^{*}}{q\left(\bar{p}^{*}\right)} . \boldsymbol{F}+\boldsymbol{G}$ can therefore be re-written as $\left(0.5\left(\hat{p}^{*}+\bar{p}^{*}\right)-c\right) \epsilon_{p}\left(\hat{p}^{*}-\bar{p}^{*}\right) \frac{q\left(\bar{p}^{*}\right)}{\bar{p}^{*}}$.

Using the lettered areas on Figure 1(c) and Figure A.1(c) for reference, the change in Social Welfare can be expressed as follows. Note that I rename "Reduction in Benefits" to "Fewer Transactions in WIC Market," in order to make a comparison with the non-WIC market.

$\Delta$ Social Welfare $=\lambda$ Gov't Savings from Reduction in Mark-Up and Benefits

- Loss in Surplus from Fewer Transactions in WIC Market

- Loss in Surplus from Fewer Transactions in non-WIC Market

$$
\begin{aligned}
& =\lambda(\boldsymbol{A}+\boldsymbol{C}+\boldsymbol{D})-(\boldsymbol{B}+\boldsymbol{C})-(\boldsymbol{F}+\boldsymbol{G}) \\
& =\left(\alpha-\lambda v^{*}\right)(\Delta B)+\lambda\left(v^{*}-\hat{p}^{*}\right) B\left(\hat{p}^{*}\right)+\left(0.5\left(\hat{p}^{*}+\bar{p}^{*}\right)-c\right) \epsilon_{p}\left(\hat{p}^{*}-\bar{p}^{*}\right) \frac{q\left(\bar{p}^{*}\right)}{\bar{p}^{*}}
\end{aligned}
$$

Re-writing the expression in this way illustrates that the only parameters needed to assess EBT or a similar price discrimination reform are the marginal excess burden and the extent to which the volume of transactions declines following the regulation of price discrimination.

Finally, note that my analysis of the welfare effects of EBT links my paper to canonical theoretical work on the regulation of third degree price discrimination (Schmalensee 1981; Varian 1985; Ireland 1992; Aguirre, Cowan, and Vickers 2010). A central result from this literature is that disallowing price discrimination results in welfare loss only in cases in which overall output decreases. In my setting, WIC customer demand is inelastic and so does not change after EBT. For non-WIC customers, demand falls in response to the increase in the non-WIC price. Therefore, there is an unambiguous decrease in transactions (i.e., output). The decrease in transactions by non-WIC customers leads to a decrease in welfare of $\boldsymbol{F}+\boldsymbol{G}$. Incorporating the dynamic decision by WIC stores to drop out of the program leads to further reduction in transactions and a decrease in welfare of $\boldsymbol{B}+\boldsymbol{C}$. However, because WIC consumption is financed by government funds, which are costly, the overall effect on social welfare 
depends additionally on the marginal excess burden.

\section{Data}

In this section, I describe the various data sources used to estimate the effects of EBT on social welfare.

\subsection{Administrative Data on WIC Stores}

I received data on all vendors that provided food to WIC recipients during fiscal years 2007 to 2010 from the Texas Department of State Health Services (DSHS). For each fiscal year, the data include vendor name and address, vendor type, whether the vendor was new to WIC, total months of participation, and information on monitoring and compliance activities conducted during the year. Vendors are categorized as one of the following types: retail grocers (95.5\% of stores in the sample), WIC-only stores (3.1\%), Above-50 stores (0.9\%), pharmacies that provides specialized infant formula (0.5\%), or military commissaries $(0.5 \%)$. I limit my sample to retail grocers, as the remaining vendor types operate outside of the retail grocery market and therefore are not well-represented by my store profit model above. I use the excluded types to create placebo analyses of my main results.

If a WIC store participated for fewer than 12 months in a given fiscal year, I back out which months they participated using information on whether they were new in that year. In particular, if a store participated for $m<12$ months in a given year and was new to WIC, I obtain its first month of participation by counting backwards $m$ months from the end of the year. If a store participated for $m<12$ months in a given year and was not new to WIC, I count forward $m$ months from the start of the fiscal year to obtain its last month of participation ${ }^{25}$ I match stores across fiscal years based on physical address (which is reported in a more consistent format across years than store name). Finally, I expand the data from the store-fiscal year level to the store-fiscal year-month level.

Next, I impute whether a WIC store is a chain based on the following criteria: (1) the store's name includes an outlet number, thereby indicating multiple outlets per retailer (for example, "H-E-B \#39" is outlet \#39 for the Texas chain H-E-B) or (2) at least two stores have the same name in the given fiscal year. To mitigate classification error, I take the mode of this chain indicator across the months the store participates in WIC. Out of 3,015 grocers that participated in WIC during FY 2007-2010, I code 2,585 as chains and the remaining 458 as independent stores.

Lastly, I add data on the average share of households living under the Federal Poverty Line in each store's ZIP code from 2006 to 2010 (Census Bureau 2011a). I use these data to test whether store dropout after EBT varies by local poverty level.

Table A.2 reports summary statistics. Each observation is a grocery store that participated in WIC in Texas at some point during FY 2007 to 2010. I stratify the sample by chain vs. independent status as well as by ZIP code poverty $(<20 \%$ or $\geq 20 \%)$. I use $20 \%$ as a cutoff value for ZIP code poverty because it is approximately the median rate across stores. Independent WIC stores are more likely to serve high-poverty ZIP codes, whereas chain WIC stores are less likely to serve high-poverty ZIP codes.

\footnotetext{
${ }^{25}$ This method was recommended to me by by MaryAlice Winfree, Manager, Food Issuance Branch at Texas WIC. Stores participate continuously until they drop out.
} 
Independent WIC stores also participate for fewer months, on average, than chain stores ${ }^{26}$

The remaining variables summarized in Table A.2 pertain to compliance activities. For each year, the data report whether a WIC store was flagged for suspicious behavior, whether it received a compliance investigation, and whether any sanctions were applied ${ }^{27}$ If a store was flagged for suspicious behavior or received a sanction, explanatory codes are provided. I group codes together in categories that relate to price discrimination, substitution of ineligible products, and participant fraud, which relate to treatment effects of EBT, as discussed above.

Specifically, I define "Flagged for Suspicious Redemptions" to include: "Unusually high average prices — submitting extremely high average food instruments compared with similar stores"; "Extremely small amount of variation in food instrument prices — the individual food instrument prices do not vary substantially from the average price"; "High WIC to Food Stamps redemption ratio"; and "Volume of WIC business." I define "Flagged for Participant Behavior" to include "Participant/other complaints," "Large number of participants redeeming food instruments outside of their health service area," "Large number of participants redeeming food instruments who are considered to be at high health risk," "Large number of food instruments with consecutive serial numbers," "Large percentage of manually issued food instruments." All other "high-risk" flags are either unspecified ("Other") or never indicated ${ }^{28}$ A list of explanatory codes is also provided if the store received sanctions. These codes include "Overcharging" (i.e., price discrimination) and "Providing Ineligible Foods."29

Table A.2 reveals that stores in high-poverty areas and independent stores are much more likely to be flagged for suspicious redemptions. By comparison, there are very few flags for participant behavior, in line with evidence discussed above that participant fraud is rare in WIC (GAO 1999). Among stores flagged as high-risk, only $7.7 \%$ received compliance investigations, suggesting that enforcement resources may be limited.

Nearly all sanctions in the data are for price discrimination, rather than providing ineligible products. Among independent WIC stores in high-poverty ZIP codes that received compliance investigations, $20.0 \%$ were found to be price discriminating. By comparison, only $5.9 \%$ of independent WIC stores in lower poverty areas that received investigations were found to be price discriminating. Among chain

\footnotetext{
${ }^{26}$ Note that "months of participation" is bounded above at 48, as I observe four years of participation at most (FY 2007-2010).

${ }^{27}$ Note that because compliance investigations may take several years, a flag reported in one year is not necessarily related to a sanction applied in the same year.

${ }^{28}$ These are: "Large percent of food instruments redeemed at same price," "Redeemed prices are higher than their price list" (price lists are used for pharmacies providing formula), "Large percent of high-priced food instruments," "Large increase of dollar volume of food instruments redeemed over time," "Large percent of the area's total WIC redemptions," "WIC sales are an unusually high percentage of vendor's total sales," "High WIC to Food Stamps redemption ratio," "WIC and Food Stamp sales are an unusually high percentage of total sales," "Excessive number of returned checks due to errors, " "Past history of violations and disqualifications," "Associations with known violators," "Multiple ownerships which include known violators," "Short on authorized food items or no inventory," "New Vendor," "Random selection of vendors," "Other.").

${ }^{29}$ The other sanction explanations are either never indicated or indicated for one store/year observation only: "Food Stamp Program Reciprocal Action," "Receiving/Transacting or Redeeming Food Instruments Outside Authorized Channels" "Providing Credit or Non-food Items in Exchange for Food Instruments," "Trafficking," "Alcohol/Tobacco" (that is, exchanging vouchers for alcohol or tobacco), "Charging for Supplemental Foods Not Received," "Reimbursement in Excess of Documented Inventory."
} 
WIC stores, the same percentages are $9.7 \%$ and 3.8\%, respectively. Therefore, variation in local poverty appears to explain an important part, although not all, of the difference in price discrimination between independent and chain WIC stores.

Lastly, I use the data to create maps in order to visualize the geographic density of WIC stores at the start of the sample. Figure A.6 displays two maps side-by-side. The map on the left shades ZIP codes according to total WIC stores in October 2006 (the first month of the sample), while the map on the right shades ZIP codes according to total WIC stores per poor households in October 2006. These maps suggest that participant access is quite limited in some areas - for example, many ZIP codes have 0 WIC stores, or less than 1 per 1,000 poor households. Therefore, it seems plausible that a reduction in WIC stores could lead to a decline in benefit take-up.

\subsection{Nielsen Homescan Consumer Panel}

The Nielsen Consumer Panel tracks purchasing behavior among a large, nationally representative sample of households. Panelists provide data about all products they buy, from any outlet, including each product's price, the quantity purchased, and the store at which the purchase occurred. Panelists also provide demographic information on an annual basis, including ZIP code of residence. I use these data to evaluate Prediction 3, which states that WIC stores will increase the prices charged to non-WIC shoppers after EBT.

After returning home from a shopping trip, Nielsen panelists initiate a data entry. They first enter the total amount spent, inclusive of taxes, as printed at the bottom of their sales receipt. They then enter the date and the store at which the trip took place. Next, they use optical scanners provided by Nielsen to input the UPC of each product purchased. For each product, they then enter its price (if prompted), the value of any discounts, and the quantity purchased 30 Importantly, WIC purchases (i.e., those tendered with vouchers or EBT cards) should not be be included in the data because they do not involve a traditional sales receipt in Texas. Before EBT, the WIC transaction bypasses the ECR altogether. After the introduction of EBT, the ECR prints out a list of the recipient's remaining quantities, in place of a sales receipt. Even so, my results are robust to dropping the subset of households most likely to be eligible for WIC.31

I obtained the Nielsen Consumer Panel for the years 2006-2009. I first restrict the data to households that reside in Texas during these calendar years. I then keep purchases that occur from FY 2007 to FY 2009 - this step is necessary because I will merge in data from the administrative WIC store sample, which starts in FY 2007.

My identification strategy involves comparing the prices of WIC products charged before and after EBT by stores that participate in WIC. To identify WIC products, I use the rules listed in Table A.1. I encode these rules using a set of "product attribute" variables available in the Nielsen data (e.g., package size, product type, etc.). Importantly, these variables are never missing. I also define a subset of

\footnotetext{
${ }^{30}$ If the shopping trip took place at a store with which Nielsen has an independent data sharing agreement, the price prompt is bypassed and Nielsen later fills in the price. In some cases the imputation of prices by Nielsen may result in an error in which purchases in one week are assigned prices from the next week (from the same store). This issue should have a limited effect on my estimates.

${ }^{31}$ Results available upon request.
} 
"similar" non-WIC products for use in placebo analyses. This subset includes UPCs that are ineligible for WIC but which belong to a product group (defined by Nielsen) that includes at least one WIC $\mathrm{UPC} 32$

As for WIC stores, data limitations require me to impute whether a store participates in WIC based on its location and to potentially group some stores together due to catch-all retailer codes provided by Nielsen. Since in those cases the composition of stores can change in unobserved ways, I test sensitivity to excluding these stores in my empirical analyses.

Nielsen does not release identifying information on stores. Instead, the data include a de-identified retailer code, which corresponds to the individual outlet for independent stores and the parent company for chain stores, except in some cases in which it is a catch-all code indicating "all other stores" in one of 65 retail channels (e.g., "all other convenience stores"). For chains with which Nielsen has a data-sharing agreement, an outlet code is also provided. I code a retailer as a chain if a retailer and outlet code are provided. This method will tend to misclassify smaller chains with which Nielsen does not have a current or prior data-sharing agreement.

I then proxy for whether a purchase in the Nielsen data occurred at a WIC store with an indicator for whether a store of the given size (chain, independent) participated in WIC in the year of the purchase and the ZIP code of residence of the panelist shopper. I observe whether there are WIC stores in a given ZIP code and year from the administrative WIC store sample, described above. Next, I create a store ID equal to the unique combination of retailer code, outlet code (where provided), and county-group of residence of the panelist shopper (where all counties in a group have the same EBT date). I included county-group of residence in the ID to prevent against cases in which a smaller chain or "all other" subgroup that spans multiple county groups is represented by a single retailer code (fixed effect) ${ }^{33}$ Finally, I impute a store's county based on the county of residence of the panelist shopper.

Although my indicators for chain status and WIC store participation will contain some measurement error, the fact that I am able to difference across counties and dates should serve to net out some of this error. At the end of this section I also provide direct evidence that error in the WIC store proxy is limited.

Table A.3 displays summary statistics for the sample of WIC and non-WIC expenditures in WIC and non-WIC stores. I calculate price per unit by subtracting the value of coupons or discounts from the total price paid for a given item and then dividing by the number of units purchased. Prices are higher in single outlets, which may be due to higher costs or differing composition of goods. Among expenditures at single outlets, only $13.3 \%$ occur at WIC stores (which may indicate that many small stores choose not to participate in WIC) and $\frac{3.6}{13.3}=27.1 \%$ of these expenditures are on WIC eligible products. For chain stores, $82.2 \%$ of expenditures occur at WIC stores and $\frac{29.4}{82.2}=35.8 \%$ of these are of WIC products.

Note that the Nielsen sample provides good coverage of areas in which WIC stores are located. For

\footnotetext{
${ }^{32}$ Product groups with at least one eligible UPC are as follows: Baby Food (includes infant cereal and formula); Eggs; Jam, Jellies, and Spreads (includes peanut butter); Seafood- Canned (includes tuna); Vegetables - Canned (includes canned carrots); Fresh Carrots; and Vegetables and Grains - Dried (includes beans) before 10/2009 only.

${ }^{33} \mathrm{My}$ results are also robust to using county or ZIP code of residence of the panelist shopper in place of county group.
} 
FY 2007, at the start of the sample, 859 ZIP codes had chain WIC stores and 234 ZIP codes had single outlets, out of roughly 2,500 ZIP codes total in Texas. By comparison, in the Nielsen sample, for FY 2007, I observe purchases of WIC products in WIC chains by panelists who live in 728 of these ZIP codes (85\% coverage) and, for single outlet WIC stores, by panelists who live in 156 of these ZIP codes (67\% coverage).

Lastly, I provide evidence on the extent of measurement error in the WIC store proxy using Census establishment counts. Note that there is no measurement error if all grocery stores of a given size in a given ZIP code either participate or don't participate. To count total grocery stores per ZIP code, I use establishment counts from the 2010 Census (Census Bureau 2010, , NAICS code 44511). Unfortunately, these data do not differentiate between independent and chain stores. Therefore, I calculate the average share of grocery stores per ZIP code that were chains vs. independents using the Nielsen data. ${ }^{34}$ I combine the Nielsen "share" variable with the Census store counts to get an approximation of the total number of chain and independent stores per ZIP code.

Among ZIP codes with at least one independent WIC store from FY 2007-2010, there were 1.2 independent WIC stores on average (from the administrative store sample). By comparison, using the method outlined above, I estimate that there were 1.1 total independent grocers in these same ZIP codes in 2010. The respective numbers for chain stores are $2.3 \mathrm{WIC}$ stores and 2.8 grocery stores per ZIP code. These comparisons indicate that, especially for independent stores, all grocers per ZIP code tend to participate or not participate, suggesting measurement error in the WIC store proxy is limited.

\subsection{Texas Birth Certificate Data}

My third source of data is the universe of birth certificates from the state of Texas for the years 2005 to 2009, which I obtained from the Texas DSHS. These data include detailed demographic information, including mother's county of residence, and, importantly for my purposes, information on maternal WIC participation. I drop cases in which the mother resided outside of Texas (1.87\% of observations) or in a county without an EBT date (0.05\%). In addition, I drop births with missing values of WIC participation $(0.57 \%)$ or gestation length $(0.07 \%)$. The final sample consists of 1,984,913 births.

Since 2005, the Texas birth certificate has asked mothers to respond "yes" or "no" to the following question: "Did you receive any WIC food during your pregnancy?" The share that responded "yes" in my sample is $53.4 \%$. Note that this measure of take-up is extensive margin and therefore will tend to understate more intensive margin aspects of utilization, including how much food a mother received, or how many months she participated.

Individuals may under-report program participation for a number of reasons, including welfare stigma (Moffitt 1983; Meyer, Mok, and Sullivan 2015). To assess the quality of the WIC self-report on the birth certificate, I obtained monthly enrollment counts for Texas WIC from the USDA for fiscal years 2006 , 2008, and 2009. ${ }^{35}$ During these years, an average of 102,622 pregnant women participated in Texas

\footnotetext{
${ }^{34}$ Note that the Nielsen Consumer Panel is a representative subsample of households and does not necessarily record the universe of stores a given ZIP code (i.e., stores are only included if panelists shop at them). This issue introduces some error in these calculations.

${ }^{35}$ I used The Wayback Machine webcrawler to locate these data, and the webcrawler does not have a record for FY 2007, which is why it is omitted from these years. The website for the USDA data is: http://www.fns.usda.gov/pd/
} 
WIC per month. In order to make these counts, which are measured as a flow, comparable to the WIC participation measure from the birth certificate, which is measured as a stock, it is necessary to incorporate additional information on enrollment rates per trimester. The USDA reports that about $50 \%$ of pregnant WIC participants enroll during the first trimester, compared with $40 \%$ in the second trimester, and $10 \%$ in the third trimester (a distribution that has stayed relatively constant over time Thorn et al. 2015). Supposing that none of these women enroll in their first month of pregnancy and that the share enrolled increases linearly across months within a given trimester, then the average share enrolled in any given month of pregnancy is $66 \%\left(\frac{0+0.25+0.50+0.63+0.76+0.90+0.93+0.97+1}{9}=0.66\right)$. There were 400,722 births per month in Texas during fiscal years 2006, 2008 and 2009. Since pregnancy lasts around $3 / 4$ of the year, about 300,542 women were pregnant each month. Then, given the average monthly enrollment of 102,662, approximately $34 \%$ of pregnant women participated each month. Dividing $34 \%$ by $66 \%$ implies that $52 \%$ of pregnant women in Texas participated in WIC during their pregnancy, which is nearly identical to the birth certificate participation rate of $53 \%$.

Next, I create an index of maternal poverty using three indicators of low-SES status: mother is a minority (defined as non-white Hispanic or black), mother is unmarried, and mother has a high school education or less. Such an index is necessary because maternal income is not directly reported on the birth certificate. I first standardize each indicator by subtracting the sample mean and dividing by the standard deviation. I then average the three standardized variables together to create the poverty index. By combining the indicators in this way, I am able to avoid the issue that there are multiple potential proxies for household poverty in the data (and a decision rule for which indicator to use is not clear $a$ priori).

I create an indicator for "high-poverty" status that is equal to 1 if the index exceeds 0.5 (the 75 th percentile by construction). As would be expected, WIC participation is much higher among "highpoverty" mothers (79.9\%) than those in the remainder of the sample (44.8\%). I use this indicator to test whether the effects of EBT on take-up vary by maternal poverty.

Lastly, for ease of computation in the regression analyses, I collapse the data to the level of county of maternal residence and year and month of birth. For each cell, I calculate total births, total births to mothers who participated in WIC, total births to high-poverty mothers, and total births to high-poverty mothers who participated in WIC.

\section{Empirical Method}

\subsection{EBT Implementation in Texas WIC}

In 1997, following the successful implementation of EBT in the Texas SNAP program, the Texas State Senate passed a bill requiring the Texas Department of Health (TDH) to "analyze the cost-effectiveness of using EBT in conjunction with ... the federal special supplemental food program for women, infants, and children." ${ }^{36}$ The resulting investigation by TDH concluded that EBT would streamline the processes

\section{wicmain.htm.}

${ }^{30}$ Text of the original bill 910: http://www.tlc.state.tx.us/docs/sessions/75soe.pdf. Information presented in this subsection comes from email correspondence with Ray Krsezniak and Leona Duong at Texas WIC and "Texas WIC EBT Newsletter \#1," Jan 2002, available here http://web.archive.org/web/20071120090627/http://www.dshs. 
of benefit distribution, food redemption and grocer payment in the WIC program. Texas then partnered with New Mexico to conduct a joint pilot of EBT in a few contiguous border counties in June 2005. ${ }^{37}$ Following the pilot, TDH received state and federal approval in September 2005 for statewide expansion. EBT was introduced to different groups of counties on different dates during the years 2005-2009. The rollout proceeded in two phases separated by a seven-month break in between due to an upgrade in EBT card technology. The first phase occurred from June 2005 to October 2006 and included two densely-populated urban counties in the Dallas-Fort Worth area (Grayson and Collin Counties) and two groups of rural counties covering West Texas and the Texas Panhandle. The second phase, running from June 2007 to March 2009, introduced EBT to the remaining 148 out of 254 counties. Table A.4 lists the full rollout schedule, including the pilot in June 2005, and Figure A.2 is a visualization of the expansion, in which counties with later rollout dates are shown in a darker shade of blue ${ }^{38}$ Note that, because my samples of WIC stores and Nielsen prices start in FY 2007 (10/2006), only the second phase will provide identifying variation in my analyses of these data. I am, however, able to include the first phase in my analysis of the births sample, which starts earlier (2005) (I also test the sensitivity of the births results to excluding counties with EBT dates in the first phase).

My identification strategy relies on the assumption that the exact timing of EBT rollout is uncorrelated with county-group level trends. Of importance, then, is to understand the process through which EBT dates were assigned to counties. In fact, EBT dates for each phase, which were announced prior to the start of the respective phase, were chosen based on the assessment of local WIC staff as to when the WIC stores in their area would be "EBT-Ready" (i.e., able to process EBT transactions). This method seems like it could be related to the local retail environment, so I include county-group specific linear time trends in all of my regression analyses as added robustness against confounding trends. An initial check of whether EBT timing is related to local economic measures is whether the path of EBT rollout (Figure A.2) seems related to local poverty levels (Figure A.5). This comparison does not definitively rule out a correlation. Therefore, it is important to directly test whether the timing of EBT is correlated with county-level trends, as I do in the next section.

Finally, note that the date assigned to a given county represents the first month that EBT cards were issued to participants and used in stores within that county. It is therefore the date grocers and WIC clinics began utilizing the new technology, although they were both required to be able to process claims ("EBT ready") 30 days prior to the rollout date. Still, store incentives for pricing and participation changed precisely on the EBT date, and so I define treatment as on or after the rollout month across all samples.

state.tx.us/wichd/ebt/pdf/news/2002_feb_txwicebtnewsletter.pdf.

${ }^{37}$ In Texas, the pilot was conducted in the counties of El Paso and Hudspeth. In New Mexico, the pilot was conducted in the neighboring cities of Truth or Consequences and Hatch.

${ }^{38}$ There are 14, sparsely populated, counties for which there were 0 WIC stores during EBT rollout. These counties were consequently not assigned an EBT date and I drop them from all of my samples, using the remaining 239 for identification of the causal effects of EBT. 


\subsection{Empirical Specification}

In order to assess the causal effects of the switch from paper vouchers to EBT, I exploit variation in the exact timing of EBT implementation across counties in Texas in a difference-in-differences model. This model compares store and participant outcomes that occur after the rollout date in a given county to those that occur before.

My main estimating equation takes the following general form:

$$
Y_{y m i}=\alpha+\beta \text { AfterEBT } T_{y m i}+\mu_{i}+\gamma_{y m}+\nu_{i} * t+\epsilon
$$

for a given outcome $Y$ in fiscal year $y$, month $m$ and geographic unit $i$. Note that $i$ is a placeholder that refers to either county $c$ or store $s$. After $E B T_{y m i}$ is an indicator that equals 1 if $y m$ is after the EBT rollout date in the county corresponding to $i$. Because counties implemented EBT at different times, my design enables me to control for unrestricted year-month effects, $\gamma_{y m}$, unrestricted county or store fixed effects $\mu_{i}$, and county-group specific linear trends in fiscal year, $\nu_{i} * t$ (where county group refers to all counties with the same rollout date) ${ }^{39}$ The parameter of interest is $\beta$, the effect of EBT on $Y_{y m i}$, which is identified off of variation across counties and dates. $\epsilon$ is the error term, which I cluster by county across all specifications.

Note that when using the birth certificate data, I set ym equal to birthdate so that AfterEB $B T_{y m i}=1$ implies the birth occurs after the EBT rollout date in county of residence $i$. I choose birthdate rather than conception date because the majority (about half) of pregnant mothers in WIC do not enroll until their second or third trimester, so a reduction in stores partway through pregnancy can affect take-up (Thorn et al. 2015).

In Section 3 , I hypothesize that stores face higher fixed costs of joining WIC in poorer neighborhoods. To test this hypothesis, I estimate an alternative form of Eq. 3 in which I interact AfterEBTymi with the share of households per ZIP code that live in poverty, which I denote PovZIP $P_{i}$, as shown below.

$$
Y_{y m s}=\alpha+\beta_{z} \text { AfterEBT } T_{y m s} * \operatorname{PovZIP}_{s}+\beta \text { AfterEBT } T_{y m s}+\mu_{s}+\gamma_{y m}+\nu_{s} * t+\epsilon
$$

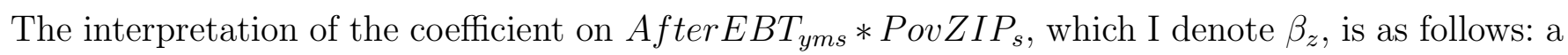
1 percentage point increase in the share living in poverty in a given ZIP increases $Y_{y m s}$ by $\beta_{z} / 100$. Store fixed effects control for the level effect PovZIP .

For my identification strategy to yield causal estimates of the effects of EBT, it is important to establish that the timing of rollout appears to be exogenous. Event-time figures are commonly used to detect the presence of pre-trends in $Y_{y m i}$, which would provide evidence against exogeneity (e.g., Kline 2011; Almond, Hoynes, and Schanzenbach 2016). In my setting, event-time $t$ is the difference in months between a given date ym and the EBT rollout date in county $i$. Because my samples are unbalanced in event-time, coefficient estimates for large or small values of event-time will tend to give unequal

\footnotetext{
${ }^{39}$ I use county-group linear trends, rather than county-level trends, to prevent the error-covariance matrix from being singular, given the high number of counties (239) relative to county-year-month cells. Coefficient magnitudes are highly robust to either set of time trends, however.
} 
weight to counties implementing EBT early or late in the sample. It is therefore important to define a window in which the sample of counties is approximately balanced (Kline 2011). For a given event-time window $w$, I define the following event-time indicators: $t<-w, t=-w, t=-w+1, \ldots, t=-2, t=$ $0, t=1, \ldots, t=w-1, t=w, t>w$. The omitted (reference) indicator is $t=-1$, the period before rollout. Bracketing event-time values outside the window reduces collinearity between event-time and year-month fixed effects. I re-estimate Eq. 3, replacing AfterEBT $T_{y m i}$ with the event-time indicators, and graph the resulting coefficients for $t$ from $-w$ to $w$.

For counties implementing EBT on or before the first month of each data sample, AfterEBT $T_{y m i}$ is equal to 1 for all observations. These counties are not used to identify the coefficient on AfterEBT $T_{y m i}$, but may be used to identify some of the coefficients for positive event-time values (if implementation occurs less than $w$ months before the start of the sample). For these counties, which cannot be part of a balanced sample in event-time, I set all event-time indicators equal to 0. For the store and pricing samples, these are the Phase 1 counties and, for the births sample, these are the pilot counties. Note that no implementation dates occur after the last month of any of my samples.

For the administrative WIC store sample, which covers FY 2007-2010, I define the window such that $w=12$, thereby creating a balanced sample for all Phase 2 counties except for one county-group that has a pre-period of 9, rather than 12 months. For the Nielsen pricing sample, a window of $w=6$ is balanced in event-time for Phase 2 counties and, for the births data (1/2005-12/2009), which extend 3 months later, a window of $w=9$ is balanced in event-time for all non-pilot counties.

Next, I provide a series of tests of the identifying assumption - that the timing of EBT rollout is exogenous. In these tests, I estimate Eq. 3, setting the outcome $Y_{y m i}$ equal to a series of economic and demographic indicators at the county level. If rollout is correlated with these measures, that would suggest a violation of the exogeneity assumption, meaning my causal estimates may be confounded by spurious effects.

I first use the birth certificate data to construct a series of indicators reflecting the demographic composition of births. In particular, I calculate the share of births per county, year, and month for which the mother has each of the following characteristics: non-white Hispanic, non-Hispanic black, age $<20$, age 20-24, age 25-29, age 30-34, married, no high school diploma, high school diploma, some college, and reported occupation. I also calculate the average poverty index per county, year, and month.

I then estimate Eq. 3 for each of these outcomes, setting $\mu_{i}$ equal to a vector of county fixed effects and weighting each regression by total births per county, year, and month (i.e., the denominator of the outcome variable). Tables A.5 and A.6 present the results. The coefficients on "After EBT" are uniformly small and imprecise, suggesting that my estimates of the causal effects of EBT on WIC participation are not driven by underlying shifts in the demographic composition of births.

Next, I estimate an analogous set of regressions for a series of economic indicators at the county level. I obtained data on income per capita, earnings per capita, employment per population and the SNAP participation rate (BEA, 2010; Census Bureau 2017, respectively). Note that, unlike the birth certificate data, which are reported monthly, these data are reported annually, in either June (BEA data) or July (SNAP data). I therefore interpolate each series to be linear in month around the reporting month (June 
or July) of each year.

Table A.7 presents the results. The coefficients are uniformly small and statistically insignificant. These results suggest that rollout timing is unrelated to local economic factors that could independently affect pricing and program participation outside of the direct effects of EBT 40

Additionally, I test whether the timing of EBT implementation is related to clinic closures that occurred during my sample period and resulted in reductions in participation (Rossin-Slater 2013). I use the dataset from Rossin-Slater (2013) to calculate the sum of WIC clinics per county, year, and month for 10/2006-12/200941 I then estimate Eq. 3, setting $Y_{y m i}$ equal to the sum of WIC clinics and $\mu_{i}$ equal to a vector of county fixed effects. The results, shown in Table A.8, do not suggest a relationship between EBT and clinic closures.

Finally, note that my use of a staggered, county-level rollout design links my paper to recent work on the effects of nutrition assistance programs. For example, Hoynes, Page, and Stevens (2011) exploit county-level variation in the introduction of the WIC program in the 1960s to study its effects, finding that it led to increases in birthweight. Similarly, Almond, Hoynes, and Schanzenbach (2011) and Almond, Hoynes, and Schanzenbach (2016) study the staggered, county-level rollout of the Food Stamps Program in the 1960s and 1970s, showing that it increased birthweight and reduced the incidence of disease later in life.

\section{$7 \quad$ Results}

\subsection{Effect of EBT on Price Discrimination}

If EBT eliminates the ability to price discriminate among WIC stores, then it should be that compliance investigations conducted after EBT do not result in sanctions for price discrimination. I cannot test this prediction directly using my data on compliance outcomes because the data only report the year in which a compliance investigation was concluded, and investigations can take up to 3 years (so the timing of actual violations is unobserved). Still, it should be that investigations that concluded after EBT (some of which would also have been initiated after EBT) resulted in fewer sanctions for price discrimination than those that concluded before EBT. Indeed, among compliance investigations that concluded after EBT, only 3.4\% resulted in a sanction for price discrimination, versus $13.0 \%$ of those that were concluded prior to EBT. These results are consistent with the idea that EBT eliminates price discrimination.

\subsection{Effect of EBT on Store Participation in WIC}

The model predicts that some stores should drop out of WIC after EBT, particularly those that exhibit a higher level of price discrimination prior to EBT (i.e., independent stores, rather than chains). I test this hypothesis by estimating Eq. 3, setting $Y_{y m i}$ equal to total WIC stores per county-year-month and $\mu_{i}$ equal to a vector of county fixed effects. I estimate separate regressions for independent and chain

\footnotetext{
${ }^{40}$ As an added sensitivity test, I report effects for two different subsets of years: FY 2007-2010, corresponding to the store and pricing samples, and 2005-2009, corresponding to the births sample.

${ }^{41}$ This range of dates is the overlap between the most common sample period I use (FY 2007-2010, or 10/2007-9/2010) and the years of the clinic data from Rossin-Slater (2013) (calendar years 2005-2009).
} 


\section{WIC stores.}

The results are shown in Table 2. The estimated coefficient implies a reduction in independent WIC stores per county of 0.11 after EBT rollout, or $10.7 \%$ of the sample mean. For chains, the coefficient is also negative, at -0.06 , but small relative to the mean $(0.8 \%)$ and statistically insignificant.

Figures 2 and 3 display coefficients and 95\% confidence intervals from corresponding event-time regressions. Figure 2 shows a drop in independent WIC stores on the EBT date as well as a decrease in the first few months that follow. The latter effect may indicate that some stores learned about the magnitude of the profit reduction in the months after rollout. Conversely, there is no clear drop among chains. In both figures, there are no observable pre-trends, providing support for the exogeneity assumption.

A reduction in total WIC stores could be due to existing stores dropping out or fewer would-be stores joining the program. However, Prediction 1 specifically implies that existing WIC stores should be more likely to drop out after EBT. To test this hypothesis, I use the WIC store data in panel form and estimate the effect of EBT on the likelihood that a store exits WIC. Specifically, I estimate Eq. 3 , setting $Y_{y m i}$ equal to 1 if WIC store $i$ exited on or before date $y m$ and 0 otherwise. Note that I define the month of exit as the last month of WIC participation unless that month is the last month of the panel (in which case I assume exit occurred after my sample ends). I set $\mu_{i}$ equal to a vector of store ID fixed effects (where store ID corresponds to physical address). Including store fixed effects enables me to adjust for differences in entry date, as stores that enter earlier will tend to exit earlier, all else equal.

Table 3. Columns (1) and (3), present the results, separately for chain and independent WIC stores. The likelihood that an independent WIC store exits increases after EBT by 5.4 percentage points $(14.5 \%$ of the sample mean). The effect for chain stores is small and statistically insignificant. Figures 45 display the corresponding event-time figures. Exit likelihood clearly increases after EBT for independent stores but is flat for chains (and no pre-trends are observed).

Above, I hypothesized that WIC stores in poorer areas should be more likely to drop out after WIC due to higher fixed costs. To test this hypothesis, I estimate Eq. 4, which adds to Eq. 3 an interaction between AfterEBT $T_{y m i}$ and PovZIP , the ZIP code poverty rate. The results are shown in Table 3 , Columns (2) and (4). For independent WIC stores, the coefficient on the interaction term is positive but imprecise. For chains, the coefficient on the interaction term is positive and statistically significant, indicating that an increase in ZIP code poverty of 10 percentage points increases the likelihood a store drops out by $14.7 \%$ relative to the sample mean.

Figures A.8 and A.9 display corresponding event-time figures ${ }^{42}$ For chains in poorer areas, there is a clear increase in exit likelihood at the time of EBT rollout. This evidence suggests that ZIP code poverty explains an important share of the variation in dropout behavior between chain and independent WIC stores.

Recall that my sample of WIC stores excludes certain types of WIC vendors that operate outside of the retail grocery market. These are: WIC-only stores, Above 50 stores, pharmacies, and commissaries.

\footnotetext{
${ }^{42}$ These event-time coefficients correspond to the interaction term: AfterEBT $T_{y m i} * \operatorname{Pov} Z I P_{i}$. Specifically, I estimate

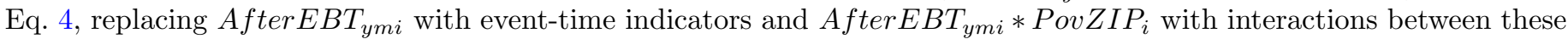
event-time indicators and ZIP code poverty. I then graph the coefficients from the interactions.
} 
Before EBT, these types of vendors were largely unable to price discriminate, due to the fact that they are reimbursed specially regulated rates (and may also serve only WIC customers). ${ }^{43}$ However, these vendors were still required to undergo the transition from paper vouchers to EBT (e.g., installing necessary technology). Therefore, if the costs of EBT outside of the loss of price discrimination are important, it should be that dropout increases among these vendors after EBT. I test this hypothesis by estimating Eq. 3, setting $Y_{y m i}$ equal to total vendors per county, year and month, and $\mu_{i}$ equal to a vector of county fixed effects. I estimate separate regressions for each type of vendor. I present the results in Table A.9, which reveals mostly positive and insignificant coefficients, suggesting that "other costs" of EBT are limited.

\subsection{Effect of EBT on Prices Paid by Non-WIC Customers}

Prediction 3 states that WIC stores that price discriminate before EBT should increase the prices they charged non-WIC customers for WIC products after EBT (i.e., $\hat{p}^{*}>\bar{p}^{*}$ ). To test this prediction, I first restrict the Nielsen sample to WIC products in WIC stores. I then estimate Eq. 3, setting $Y_{y m s j}$ equal to the log price of product $j$ in store $s$ and $\mu_{s j}$ equal to two separate vectors of store and UPC fixed effects. As elsewhere, I estimate separate regressions for chain and independent WIC stores ${ }^{44}$

Table 4 presents the results. In independent WIC stores, the price of WIC products increases $6.44 \%$. For chain WIC stores, the effect on prices is small (0.10\%) and statistically insignificant. These results support my prediction - recall that independent WIC stores were more likely to price discriminate than chain WIC stores prior to EBT (as shown in Table A.2). Figures 6 and 7 plot coefficients and $95 \%$ confidence intervals from corresponding event-study regressions. For independent WIC stores, the price of WIC products increases on the EBT date, whereas the graph for chain WIC stores is flat. There is no evidence of pre-trends in either figure.

Next, I test whether EBT affects prices in two "untreated" subsamples: non-WIC products in WIC stores and WIC products in non-WIC stores. There should be no direct effects on prices in these subsamples, although indirect effects may occur (e.g., if there are price spillovers from WIC to non-WIC products). Table A.10 presents the results, separately for independent stores and chains. The coefficients are uniformly small and statistically significant, except for the effect on prices of non-WIC products in chain WIC stores (-1.02\%, significant at 1\%). In Figures A.10 A.13, I present corresponding event-time figures. In each figure, there is no change in prices on or after the EBT date. Notably, the graph of non-WIC products in chain WIC stores is quite flat around the EBT date (Figure A.11). In addition, there is very little evidence of pre-trends. Taken together these results provide important support for my predictions as well as the validity of my identification strategy.

Next, I estimate the impact of EBT on the prices of WIC products in WIC stores that drop out

\footnotetext{
${ }^{43}$ Detail on WIC-only and Above 50 stores is provided above in Section 2, Commissaries and pharmacies are reimbursed special rates. More information can be found here: https://hhs.texas.gov/doing-business-hhs/provider-portals/ wic-providers/wic-policy-procedures-manual.

${ }^{44}$ Note that my theoretical framework does not provide a clear prediction as to how the price increase should vary with local poverty, as such effects will depend on several factors including the non-WIC customer elasticity, which likely varies with household income (DellaVigna and Gentzkow 2017). Indeed, in unreported analysis, I do not find evidence of a relationship between the size of the price effect and ZIP code poverty in either the independent or chain WIC samples.
} 
of WIC after EBT. These "switcher" stores should be those that price discriminated before EBT. Therefore, the separating price they charged non-WIC customers before EBT should equal the price they charge after EBT (when they only serve non-WIC customers). To test this hypothesis, I code a store in the Nielsen sample as a "switcher" if it appears as a WIC store for at least 6 months before EBT and as a non-WIC store for at least 6 months after EBT ${ }^{45}$ I then re-estimate the price regressions on the sample of WIC products in "switcher" stores, pooling together independent and chain stores. Table A.11 presents the results, showing that there is no effect on prices, as predicted, and Figure A.14 shows the corresponding event-time figure, which is flat.

Another important question regarding "switcher" stores is whether they drop their WIC-eligible products after leaving WIC, as would be expected if there are important fixed costs associated with carrying the healthy/fresh foods required by WIC. Nielsen does not provide a direct measure of store inventory, so I create a proxy indicator equal to one if there is at least one purchase of any WIC-eligible product per month in the given store. I generate separate versions of this indicator for perishable vs. non-perishable goods as well as for WIC vs. non-WIC products. I denote the following as perishable goods: eggs, fresh produce (for carrots), and baby food. Non-perishable foods include dried legumes, spreads (peanut butter), canned seafood, formula, and canned vegetables (carrots). The sample contains both single outlets and chains, as any store that left WIC as a result of EBT should drop some of these products.

I then run the following regression, in which $\phi_{s}$ are store fixed effects, $\gamma_{y m}$ are year-month FE, and $\psi_{s} * t$ are county-group specific linear time trends. LeavesWIC $C_{s}$ is an identifier for the "switcher stores" subset, which is collinear with $\phi_{s}$ (and therefore does not appear as a separate control). Differencing enables me to control for common trends in sales, which would tend to affect my proxy for inventory.

$$
Y_{y m s j}=\alpha+\beta \text { AfterEBT } T_{y m s} * \text { LeavesWIC } C_{s}+\lambda \text { AfterEBT } T_{y m s}+\phi_{s}+\gamma_{y} m+\psi_{s} * t+\epsilon
$$

The results, shown in Table A.12, are somewhat imprecise but compelling. The coefficients suggest that "switcher" stores drop WIC goods and are more likely to carry non-WIC goods after EBT. Interestingly, this effect appears to come through a substitution away from perishable UPCs towards non-perishable UPCs, as we would expect if there are higher fixed costs associated with carrying perishable foods (e.g., refrigeration costs).

Lastly, I perform several robustness tests of the main results. First, in Table A.13, I replicate Table 4 , limiting the sample to ZIP codes in which there is no change in WIC store participation throughout the sample period (separately for chain and independent stores). Doing so provides a check as to whether error in my WIC store proxy is affecting my estimates ${ }^{46}$ Dividing the sample in this way reduces power,

\footnotetext{
${ }^{45}$ The choice of 6 months is arbitrary, and results are highly robust to other numbers of months.

${ }^{46}$ Recall that I proxy for whether an independent (chain) store in Nielsen participated in WIC with an indicator for whether there was at least one independent (chain) WIC store in its ZIP code at the time of purchase. For example, if there were two single outlet WIC stores in a given ZIP code and one dropped out of WIC after EBT, I would still code all purchases that occurred in small stores in that ZIP code as having occurred in WIC stores before and after EBT, potentially biasing the price estimates.
} 
but the magnitude of the effect on prices among small stores is concentrated in the subsample of ZIP codes in which there is no change in WIC store IDs over time.

A second concern is whether dynamic selection by stores into or out of my sample is predictive of a store's relative prices after conditioning on my controls. If so, my fixed effects coefficients could be biased by sample selection, challenging the validity of my design. I provide a direct test of such effects in Table A.14, in which I add controls for the month of entry into my sample and for the month before exit from my sample (and set these controls equal to 0 if the store is present in the first month or last month of the sample). Reassuringly, the coefficients on these indicators are insignificant.

Finally, in Table A.15, I address two issues that affect the independent WIC store sample only. In Column (1), I exclude two store types that appear in the Nielsen data for which EBT should have no effect: military stores (WIC prices are regulated) and online stores (ineligible to participate in WIC). These store types do not appear in the chain store sample. In Column (2), I additionally exclude independent WIC stores for which the retailer code indicates a retail channel rather than the individual store. Effects are robust to these changes.

\subsection{Effect of EBT on WIC Take-Up}

Recall that access to stores is limited in many areas at the start of the sample (Figure A.6). Therefore, reductions in WIC stores after EBT may cause decreases in benefit take-up among eligible households. Since stores in high-poverty ZIP codes are more likely to drop out, effects on take-up may be larger in these areas.

To test these hypotheses, I estimate Eq. 3, setting $Y_{y m i}$ equal to total WIC births per county-yearmonth and total high-poverty WIC births per county-year-month, and setting $\mu_{i}$ equal to a vector of county fixed effects. I also estimate a modified version of Eq. 3 in which I replace AfterEBT $T_{y m i}$ with two indicators: one for mothers who give birth 0-9 months after EBT (for whom the reduction in stores may or may not occur before their take-up decision) and the other for mothers who give birth $10+$ months after EBT (for whom the reduction in stores always occurs before their take-up decision).

Table 5 presents the results. The effect of EBT on total WIC births is -3.86, as shown in Column (1), or $-5.2 \%$ of the sample mean, and is significant at the $5 \%$ level. For high-poverty WIC births, the effect is -2.17 , as shown in Column (2), implying a proportionally larger decrease of $7.9 \%$ when compared to the sample mean, but is only significant at the $10 \%$ level. In Columns (2) and (4), the coefficients on the "10+ months" indicators are both statistically significant and similar in magnitude to the overall effects, indicating a long term reduction in take-up. In addition, the " $10+$ months" effects are relatively similar to the "0-9 months" effects, in line with evidence discussed above that mothers tend to enroll partway through pregnancy.

Figures 89 plot coefficients and 95\% confidence intervals from corresponding event-study regressions. In both figures, there is no evidence of pre-trends, and the decrease in WIC participation occurs on the EBT date, as expected. However, the initial decrease in participation appears to decay over time in both figures. To investigate further, in Figures A.15, A.16, I widen the right side of the event-time window to include effects farther from the EBT date (specifically, 10 to 18 months after EBT). With the wider window, it is possible to see that, especially for the sample of high-poverty WIC mothers, the decrease 
in participation is persistent, suggesting the "recovery" in Figure 9 represents a fluctuation around the new, lower mean.

Next, I perform four robustness tests of the results. First, I check whether the reduction in WIC births reflects a decrease in total births (i.e., fertility), rather than a decrease in WIC take-up. To do so, I estimate the effect of EBT on WIC births as a share of total births per county-year-month, weighting by total births per cell (the denominator). I also estimate effects for high-poverty WIC births as a share of high-poverty births. Table A.16 displays the results. EBT leads to a decline in WIC births as a share of total births, with proportionately larger effects for poor mothers, suggesting that my results are not driven by underlying changes in fertility.

Second, I test whether my results are sensitive to controlling for county-level unemployment rates (BEA, 2010). Doing so is important because my sample period overlaps with the Great Recession. The unemployment data are reported annually in June, so I interpolate the series to be linear in month around June of each year. Because the unemployment rate is expressed on a per capita basis, I estimate regressions in which the outcome is WIC births as a share of total births (as in Table A.16). Table A.18 presents the results. Controlling for the unemployment rate does not change the coefficient on "After EBT", indicating that local economic shocks are not confounding my results.

Third, as a placebo test, I re-estimate Eq. 3 using a subsample of high-SES mothers who should be unaffected by the WIC store dropout in poor areas. The results are shown in Table A.19 — the effect of EBT on WIC participation is small and insignificant, as expected. Lastly, I test whether my results are sensitive to dropping counties that implemented EBT before FY 2007-2009. These counties are not used to identify the effects in the WIC store participation and pricing analyses because those datasets start in FY 2007. The results, shown in Table A.20, are very similar to the main results in Table 5 .

How reasonable is the decrease in WIC participation of $5 \%$, given the reduction in independent WIC stores of $10 \%$ ? Note that independent WIC stores are about $20 \%$ of total WIC stores (Table A.2). Then, the share of total WIC stores that dropped out after EBT is $20 \% * 10 \%=2 \%$. Therefore, it must be that the $2 \%$ of WIC stores that dropped out after EBT served at least $5 \%$ of WIC participants before EBT. It seems plausible that single outlet WIC stores would serve disproportionately more participants than the average store, given that they are located in poorer areas where eligibility is higher and there are few grocery competitors.

\section{Welfare Calculations}

In this section, I use my estimates from the previous section to calculate the overall effect of EBT on social welfare, following Eq. 2. It is first necessary to adjust Eq. 2 for the fact that not all WIC stores price discriminated before EBT (empirically, as seen in Table A.2), despite the model's prediction that they should. I define $\rho$ as the share of WIC stores that price discriminated before EBT and multiply the second and third terms of Eq. 2 by $\rho$. Note that these terms are the government savings due to lower reimbursement rates and the loss in profits among WIC stores, respectively.

I then divide Eq. 2 by the pre-EBT value of benefits, $\bar{p}^{*} B$. Doing so expresses the change in welfare as a percent of baseline expenditures, which facilitates comparisons with other policies. The final expression 
is as follows, in which $\% \Delta B$ denotes $\frac{\Delta B}{B}$ and $\% \Delta p$ denotes $\frac{\hat{p}^{*}-\bar{p}^{*}}{\bar{p}^{*}}$. Detailed steps are shown in $\mathrm{E}$.

$$
\left.\frac{\Delta \mathrm{SW}}{\bar{p}^{*} B}=\left(\frac{\lambda v^{*}}{\bar{p}^{*}}-\frac{\alpha}{\bar{p}^{*}}\right)(-\% \Delta B)\right)+\rho \lambda\left[\frac{v^{*}}{\bar{p}^{*}}-(\% \Delta p+1)\right](\% \Delta B+1)+\rho\left(0.5(\% \Delta p)+1-\frac{c}{\bar{p}^{*}}\right)\left(\epsilon_{p}(\% \Delta p) \frac{q\left(\bar{p}^{*}\right)}{B}\right)
$$

The first two terms correspond to welfare change in the WIC market, while the last term corresponds to the non-WIC market. The parameters needed to estimate this expression are shown below. Where there is uncertainty regarding parameter values, I have chosen a value corresponding to a conservative bound on welfare loss.

- $\% \Delta p$, the percentage change in the non-WIC price after EBT of $6.4 \%$ (Table 4 )

- $\% \Delta B$, the percentage change in participation after EBT of $-5.2 \%$ (Table 5 )

- Here, I am assuming that the effect for pregnant women is similar to effects among other types of WIC participants (e.g., children). This assumption makes sense if eligible women make a one-time decision whether to participate in WIC during pregnancy. In this case, enrollment among pregnant mothers should be roughly equal to enrollment among postpartum and breastfeeding mothers ${ }^{47}$ In fact, in FY 2006, for which the data are available, $11.3 \%$ of recipients were pregnant women, compared with $13.9 \%$ of recipients who were breastfeeding or postpartum mothers. (Bartlett, Bobronnikov, and Mendelson 2007, Figure 3). These shares are similar, suggesting that error due to my assumption is limited.

- $\frac{v^{*}}{\bar{p}^{*}}$, the ratio of the voucher price to the non-WIC price, before EBT

- I do not have data on voucher prices submitted for reimbursement, $v^{*}$. Therefore, I use the fact that Texas WIC caps reimbursement prices at $120 \%$ of the average price among peer stores, and set $\frac{v^{*}}{\bar{p}^{*}}=120 \%$. In so doing, I am assuming that price discriminating stores set voucher prices equal to the maximum reimbursable price. This assumption will likely cause me to overstate savings, which should bias me against finding that EBT leads to welfare loss.

- $\frac{c}{\bar{p}^{*}}$, the ratio of cost to the non-WIC price, before EBT

- I set $\frac{c}{\bar{p}^{*}}=71.1 \%$ based on the Census Bureau's Annual Retail Trade Report for 2007, which reports profits as a percent of sales for grocery stores as $28.9 \%(=1-71.1 \%$; Census Bureau 2007. NAICS code 44511).

- $\epsilon_{p}$, the non-WIC demand elasticity

\footnotetext{
${ }^{47}$ The fact that the three groups participate for slightly different lengths of time, with pregnant women for 9 months, breastfeeding mothers for 12 months, and postpartum mothers for 6 months, makes this comparison imperfect.
} 
- I set $\left|\epsilon_{p}\right|$ equal to 1, corresponding to the fact that WIC grocers in poor areas are monopolists in my theoretical framework (Lerner 1934). If WIC grocers were more competitive, demand would become more elastic, implying greater welfare loss in the non-WIC market.

- $\frac{B}{q\left(\bar{p}^{*}\right)}$, the ratio of WIC to non-WIC sales for WIC-eligible products within price discriminating stores

- I calculate this measure based on the fact that the increase from the "separating" nonWIC price to the "pooling" non-WIC price $(\% \Delta p)$ is $6.4 \%$, and the mark-up between the WIC and non-WIC separating prices $\left(\frac{v^{*}}{\bar{p}^{*}}\right)$ is $20 \%$, as explained above. The value is therefore $\frac{6.4 \%}{20 \%}=\frac{1}{3.1}=32.2 \%$.

- $\lambda$, the marginal excess burden of raising government funds

- I use 0.3 as an estimate of the marginal excess burden, following Saez, Slemrod, and Giertz (2012). There is uncertainty regarding this value because of variation in labor supply elasticity estimates (Chetty et al. 2011), as well as the extent to which taxable income represents the correct funding source for the marginal dollar of WIC benefits, as opposed to sources financed by debt, for example.

Rather than estimating a value of $\frac{\alpha}{\bar{p}^{*}}$, the social surplus per dollar of benefits that is generated when an additional household participates in WIC, I set the expression above equal to 0 and define a "break-even" value. Plugging in the parameter estimates above, I find a break-even value of $\$ 0.33$, indicating that if the social surplus from an additional household participating in WIC is greater than $\$ 0.33$ per dollar, then EBT results in social welfare loss. If we consider only the WIC market, ignoring the third term above, the break-even value rises to $\$ 0.41$. This number is relevant because it means that it costs $\$ 0.11$ more to distribute a marginal dollar of WIC benefits than a marginal dollar of cash benefits $(\lambda \$ 1=0.3 * \$ 1)$, due to vendor responses to program incentives. Welfare loss from regulating price discrimination in the non-WIC market then reduces the cutoff for welfare loss down to $\$ 0.33$ per dollar of food benefits.

Next, I graph the implied social welfare loss $\left(\frac{\Delta \text { Social Welfare }}{\bar{p}^{*} B}\right)$ against values of $\frac{\alpha}{\bar{p}^{*}}$, as shown in Figure A.17. On the secondary axis, I graph $p$-values corresponding to a test of whether the change in social welfare is statistically different from $0{ }^{48}$ The loss in Social Welfare as a percent of the value of benefits is significantly different from 0 at the $5 \%$ level if $\frac{\alpha}{\bar{p}^{*}} \geq \$ 0.50$. When $\frac{\alpha}{\bar{p}^{*}}=\$ 0.50, \frac{\Delta \mathrm{SW}}{\bar{p}^{*} B}$ equals $-0.9 \%$ of the value of program benefits (indicating loss). If the marginal surplus exceeds $\$ 1$, the loss from EBT is greater than $3.5 \%$ the value of program benefits.

It is useful to put my estimates of the "break-even" level of social surplus per dollar of food benefits in context using recent estimates from the literature of the social value of WIC participation. Currie and Rossin-Slater (2018) estimate that participation by pregnant women generates $\$ 17,201$ on average, due to the fact that WIC lowers the incidence of very low birth weight among infants Bitler and Currie

${ }^{48}$ The test is a two-sided Wald test of the non-linear combination of coefficients. 
2005). Food benefits for pregnant mothers cost $\$ 45.79$ per month on average in 2010, or $\$ 412.11$ assuming the full 9 months of participation (Vericker, Zhen, and Karns 2013). If I add in the full continuation cost of participation during the postpartum period (12 months at $\$ 49.16 /$ month, assuming breastfeeding) and for the infant through the end of eligibility at age 5 (infant for 12 months at $\$ 49.36 /$ month and child for 48 months at $\$ 36.94 /$ month), to be conservative, then the total cost is $\$ 2955.36$. Then, participation in WIC generates $\frac{\$ 17,201}{\$ 2955.36}=\$ 5.82$ of surplus per dollar of food benefits, well above my estimated cutoffs of $\$ 0.41$ and $\$ 0.33$.

A final consideration is the extent to which Texas WIC is representative of WIC at the national level. First, note that Texas WIC comprises around $10 \%$ of participants nationwide (Martinez-Schiferl, Zedlewski, and Giannarelli 2010). The poverty rate among families in Texas in 2010 was 13.0\%, which is a bit higher than the national rate of 10.1\% (Census Bureau 2011a). The rate of take-up among eligible families in Texas is also somewhat higher than the national take-up rate (67.1\% vs. 62.6\%, respectively, Martinez-Schiferl, Zedlewski, and Giannarelli 2010). As for the number of grocery stores, there were fewer grocer stores per family in Texas in 2010 (5.5 per 10,000) than at the national level (8.4 per 10,000 Census Bureau 2010). The fact that there are more participants and fewer stores in Texas may mean that the marginal store is more important for access in Texas than in other states. Still, the calculations from the previous paragraph imply that smaller participation declines can lead to welfare loss.

\section{Conclusion}

Redistributive policy in the U.S. is often tied to specific goods and services, including housing, food and healthcare. In these settings, it is often feasible to use quantity vouchers to provide transfers. For example, quantity vouchers could be used to provide housing units with fixed characteristics (e.g., number of rooms) or a specific number of health services (e.g., preventive screenings).

As compared to value-based vouchers, which operate like cash but are restricted to a subset of eligible goods, quantity vouchers offer several important benefits. First, they can be used to more effectively control participant consumption patterns because they impose a floor on the quantity purchased of each good. Altering recipient consumption patterns is important if their unrestricted choices result in loss (e.g., in the case of a parent who purchases too few nutritious foods). Secondly, quantity vouchers can be used to hold the real value of goods transferred constant, which is important when local or temporal price variation is unobserved by the government (Bronchetti, Christensen, and Hoynes 2018).

Quantity-based vouchers offer participants the same quantities of program goods regardless of prices, making them price inelastic. Therefore, private vendors of program goods are incentivized to increase their prices, which can increase the fiscal burden of such programs. Despite these important trade-offs, there is relatively little evidence on the welfare implications of using quantity vouchers in redistributive programs. In this article, I analyze these trade-offs in the setting of the WIC Program, which provides nutritious foods in fixed quantities to low-income women and children.

I study the effects of a reform to reduce price discrimination among grocery stores that participate in the WIC Program. I find evidence that the reform was successful in reducing price discrimination, 
but also that it increased store dropout, reduced take-up among eligible pregnant women, and caused some non-WIC shoppers to pay higher prices.

Reforms such as EBT may be essential for program viability in that they help maintain program integrity (Kuziemko et al. 2015). Therefore the best policy options may be those that add on, rather than replace, EBT. For example, WIC could provide subsidies to increase vendor participation in underserved areas, either as a lump sum (e.g., for a new refrigerator) or an increased reimbursement rate. More generally, beyond the setting of the WIC program, it may be important to subsidize vendor participation when enacting cost containment reforms in quantity voucher programs if the market for the program goods is localized, non-program demand is low, and there are fixed costs associated with carrying products.

In the long term, using an alternate distribution system (other than retail grocers) may be preferable. In 1976, some states distributed WIC foods directly, via WIC clinics, and a study was completed to compare the two distribution systems. The study found that "direct distribution" resulted in lower food costs than retail distribution (Bendick et al. 1976), in line with the framework presented in this article. 


\section{References}

Aguirre, Inaki, Simon Cowan, and John Vickers. 2010. "Monopoly Price Discrimination and Demand Curvature." American Economic Review 100 (4): 1601-15.

Aizer, Anna. 2007. "Public Health Insurance, Program Take-Up, and Child Health." The Review of Economics and Statistics 89 (3): 400-15.

Allcott, Hunt, Rebecca Diamond, Jean-Pierre Dubé, Jessie Handbury, Ilya Rahkovsky, and Molly Schnell. 2018. "Food Deserts and the Causes of Nutritional Inequality." National Bureau of Economic Research Working Paper 24094.

Almond, Douglas, Hilary W. Hoynes, and Diane Whitmore Schanzenbach. 2011. "Inside the War on Poverty: The Impact of Food Stamps on Birth Outcomes." The Review of Economics and Statistics 93 (2): 387-403.

— 2016. "Long-Run Impacts of Childhood Access to the Safety Net." American Economic Review 106 (4): 903-34.

Banerjee, Abhijit, Rema Hanna, Jordan Kyle, Benjamin A. Olken, and Sudarno Sumarto. 2019. "Private Outsourcing and Competition: Subsidized Food Distribution in Indonesia." Journal of Political Economy 127 (1): 101-137.

Bartlett, Susan, Ellen Bobronnikov, and Michele Mendelson. 2007. WIC Participant and Program Characteristics 2006. Technical report WIC-06-PC. Project Officer: Fred Lesnett. Alexandria, VA: United States Department of Agriculture, Food and Nutrition Service, Office of Research, Nutrition and Analysis.

Becker, Gary S. 1968. "Crime and Punishment: An Economic Approach." Journal of Political Economy 76 (2): 169-217.

Bendick, Mark, Toby H. Campbell, D. Lee Bawden, and Melvin Jones. 1976. Efficiency and Effectiveness in the WIC Program Delivery System: The Special Supplemental Food Program for Women, Infants, and Children. Misc. Publications 1338. Alexandria, VA: United States Department of Agriculture, Food and Nutrition Service.

Besley, Timothy, and Stephen Coate. 1992. "Understanding Welfare Stigma: Taxpayer Resentment and Statistical Discrimination." Journal of Public Economics 48 (2): 165-83.

Betson, David. 2009. Impact of the WIC Program on the Infant Formula Market. Contractor and Cooperator Reports 51. Alexandria, VA: United States Department of Agriculture, Economic Research Service.

Bitler, Marianne P., and Janet Currie. 2005. "Does WIC Work? The Effects of WIC on Pregnancy and Birth Outcomes." Journal of Policy Analysis and Management 24 (1): 73-91. 
Bitler, Marianne P., Janet Currie, and John Karl Scholz. 2003. "WIC Eligibility and Participation." Journal of Human Resources 38 (4): 1139-1179.

Bitler, Marianne P., and Steven J. Haider. 2011. "An Economic View of Food Deserts in the United States." Journal of Policy Analysis and Management 30 (1): 153-176.

Blackorby, Charles, and David Donaldson. 1988. "Cash versus Kind, Self-selection, and Efficient Transfers." American Economic Review 78 (4): 691-700.

Bronchetti, Erin T., Garret S. Christensen, and Hilary W. Hoynes. 2018. "Local Food Prices, SNAP Purchasing Power, and Child Health." National Bureau of Economic Research Working Paper 24762.

Bureau of Economic Analysis. 2010. "Local Area Personal Income and Employment, Counties and States Economic Profile." https ://apps.bea.gov/iTable/index_regional.cfm, accessed on 1/1/2019. U.S. Department of Commerce.

Census Bureau. 2007. "Annual Retail Trade Survey, Gross Margin as a Percentage of Sales." https: //www . census.gov/data/tables/2012/econ/arts/annual-report.html, accessed on 1/1/2013. U.S. Census Bureau.

. 2010. "County Business Patterns, Geography Area Series, ZIP Code Industry Detail File." https : / / www2 . census . gov / programs - surveys / cbp / datasets / 2010 / zbp10detail . zip, accessed on 1/1/2019. U.S. Census Bureau.

2011a. "Poverty Status in the Past 12 Months (S1701), 2006-2010 American Community Survey 5 Year Estimates." http://factfinder.census.gov, accessed on 1/1/2019. U.S. Census Bureau. . 2011b. "Poverty Status in the Past 12 Months (S1701), 2007-2011 American Community Survey 5 Year Estimates." http://factfinder.census.gov, accessed on 1/1/2019. U.S. Census Bureau. . 2017. "County SNAP Benefits Data, Small Area Income and Poverty Estimates." https : //www . census .gov/data/datasets/time-series/demo/saipe/model-tables.html, accessed on $1 / 28 / 2017$.

Chetty, Raj, Adam Guren, Day Manoli, and Andrea Weber. 2011. "Are Micro and Macro Labor Supply Elasticities Consistent? A Review of Evidence on the Intensive and Extensive Margins." American Economic Review 101 (3): 471-75.

Collinson, Robert, and Peter Ganong. 2018. "How Do Changes in Housing Voucher Design Affect Rent and Neighborhood Quality?" American Economic Journal: Economic Policy 10 (2): 62-89.

Cunha, Jesse M, Giacomo De Giorgi, and Seema Jayachandran. 2018. "The Price Effects of Cash Versus In-Kind Transfers." The Review of Economic Studies 86, no. 1 (April): 240-281. 
Currie, Janet. 2006. "The Take-up of Social Benefits." In Poverty, the Distribution of Income, and Public Policy, edited by Alan Auerbach, David Card, and John Quigley, 80-148. New York: Russell Sage.

Currie, Janet, and John Fahr. 2005. "Medicaid Managed Care: Effects on Children's Medicaid Coverage and Utilization." Journal of Public Economics 89 (1): 85-108.

Currie, Janet, and Firouz Gahvari. 2008. "Transfers in Cash and In-Kind: Theory Meets the Data." Journal of Economic Literature 46 (2): 333-83.

Currie, Janet, and Jeffrey Grogger. 2001. "Explaining Recent Declines in Food Stamp Program Participation." Brookings-Wharton Papers on Urban Affairs: 203-244.

Currie, Janet, and Maya Rossin-Slater. 2018. "Does the WIC Program Promote Equality of Opportunity in Early Life?" Working Paper.

Davis, David E. 2012. "Bidding for WIC Infant Formula Contracts: Do Non-WIC Customers Subsidize WIC Customers?" American Journal of Agricultural Economics 94 (1): 80-96.

—. 2014. "Buyer Alliances as Countervailing Power in WIC Infant-Formula Auctions." Review of Industrial Organization 45 (2): 121-138.

DellaVigna, Stefano, and Matthew Gentzkow. 2017. "Uniform Pricing in US Retail Chains." National Bureau of Economic Research Working Paper 23996.

Duggan, Mark, and Fiona Scott Morton. 2006. "The Distortionary Effects of Government Procurement: Evidence from Medicaid Prescription Drug Purchasing." The Quarterly Journal of Economics 121 (1): 1-30.

Ellickson, Paul B. 2006. "Quality Competition in Retailing: A Structural Analysis." International Journal of Industrial Organization 24 (3): 521-40.

Ellickson, Paul B., and Paul L.E. Grieco. 2013. "Wal-Mart and the Geography of Grocery Retailing." Journal of Urban Economics 75:1-14.

Ellickson, Paul B., Stephanie Houghton, and Christopher Timmins. 2013. "Estimating Network Economies in Retail Chains: a Revealed Preference Approach." The RAND Journal of Economics 44 (2): 169-93.

Figlio, David, Sarah Hamersma, and Jeffrey Roth. 2009. "Does Prenatal WIC Participation Improve Birth Outcomes? New Evidence From Florida." Journal of Public Economics 93 (1-2): $235-245$.

Government Accountability Office. 1999. Efforts To Control Fraud and Abuse in the WIC Program Can Be Strengthened. Report to Congressional Committee GAO-RCED-99D224GAO.

Hanks, Andrew S, Carolyn Gunther, Dean Lillard, and Robert L Scharff. 2019. "From Paper to Plastic: Understanding the Impact of eWIC on WIC Recipient Behavior." Food Policy 83:83-91. 
Hoynes, Hilary W., Marianne Page, and Ann Huff Stevens. 2011. "Can Targeted Transfers Improve Birth Outcomes? Evidence from the Introduction of the WIC Program." Journal of Public Economics 95 (78): 813-27.

Hoynes, Hilary, and Diane Whitmore Schanzenbach. 2015. "US Food and Nutrition Programs." In Economics of Means-Tested Transfer Programs in the United States, Volume 1, by Robert A. Moffitt, 219-301. University of Chicago Press, October.

Huang, Rui, and Jeffrey M. Perloff. 2014. "WIC Contract Spillover Effects." Review of Industrial Organization 44 (1): 49-71.

Institute of Medicine. 2000. Framework for Dietary Risk Assessment in the WIC Program: An Interim Report from the Food and Nutrition Board. Washington, DC: National Academies Press.

—. 2006. WIC Food Packages: Time for a Change. Washington, DC: National Academies Press.

Ireland, Norman J. 1992. "On the Welfare Effects of Regulating Price Discrimination." The Journal of Industrial Economics 40 (3): 237-248.

Kamara, Sheku G., Karen Castellanos-Brown, and Richard Mantovani. 2012. Improper Payments to WIC Vendors: 2005-2008. Technical report. Project Officer: Karen Castellanos-Brown. Alexandria, VA: U.S. Department of Agriculture, Food and Nutrition Service, Office of Research and Analysis.

Khan, Romana, Ting Zhu, and Sanjay Dhar. 2018. "The Effect of the WIC Program on Consumption Patterns in the Cereal Category." Quantitative Marketing and Economics 16 (1): 79 109.

Kline, Patrick. 2011. "The Impact of Juvenile Curfew Laws on Arrests of Youth and Adults." American Law and Economics Review 14 (1): 44-67.

Kopczuk, Wojciech, and Cristian Pop-Eleches. 2007. "Electronic Filing, Tax Preparers and Participation in the Earned Income Tax Credit." Journal of Public Economics 91 (7-8): 1351-67.

Kuziemko, Ilyana, Katherine Meckel, and Maya Rossin-Slater. 2018. "Does Managed Care Widen Infant Health Disparities? Evidence from Texas Medicaid." American Economic Journal: Economic Policy 10 (3): 255-83.

Kuziemko, Ilyana, Michael I. Norton, Emmanuel Saez, and Stefanie Stantcheva. 2015. "How Elastic Are Preferences for Redistribution? Evidence from Randomized Survey Experiments." American Economic Review 105 (4): 1478-1508.

Lerner, Abba P. 1934. "The Concept of Monopoly and the Measurement of Monopoly." Review of Economic Studies 1:157-175. 
Manchester, Colleen Flaherty, and Kevin J. Mumford. 2010. "How Costly is Welfare Stigma? Separating Psychological Costs from Time Costs." Purdue University Department of Economics Working Paper 1229.

Martinez-Schiferl, Michael. 2012. WIC Participants and Their Growing Need for Coverage. Technical report. Washington, DC: Urban Institute, Income and Benefits Policy Center.

Martinez-Schiferl, Michael, Sheila Zedlewski, and Linda Giannarelli. 2010. National and StateLevel Estimates of Special Supplemental Nutrition Program for Women, Infants, and Children (WIC) Eligibles and Program Reach, 2012. Technical report. Project Officer: Grant Lovellete. Alexandria, VA: United States Department of Agriculture, Food and Nutrition Service, Office of Research and Analysis.

McLaughlin, Patrick, Tina Saitone, and Richard Sexton. 2019. "The Economics of Food Vendors Specialized to Serving the Women, Infants, and Children Program." American Journal of Agricultural Economics 101 (1): 20-38.

Meyer, Bruce D., Wallace K. C. Mok, and James X. Sullivan. 2015. "Household Surveys in Crisis." Journal of Economic Perspectives 29 (4): 199-226.

Moffitt, Robert. 1983. "An Economic Model of Welfare Stigma." American Economic Review 73 (5): 1023-35.

National WIC Association. 2011. "Delivering WIC Food Benefits via Electronic Benefit Transfer (EBT)." https://s3.amazonaws .com/aws . upl/nwica.org/Delivering_WIC_Food_Benefits_ EBT.pdf.

—. 2014. "How WIC Impacts the People of the United States of America." https://s3.amazonaws . com/aws.upl/nwica.org/unitedstates2014.pdf.

Newhouse, Joseph P. 2006. "Reconsidering the Moral Hazard-Risk Avoidance Tradeoff." Journal of Health Economics 25 (5): 1005-14.

Nichols, Albert L., and Richard J. Zeckhauser. 1982. "Targeting Transfers through Restrictions on Recipients." American Economic Review 72 (2): 372-77.

Oliveira, Victor, and David E. Davis. 2006. Recent Trends and Economic Issues in the WIC Infant Formula Rebate Program. Economic Research Report 22. Alexandria, VA: United States Department of Agriculture, Economic Research Service.

Oliveira, Victor, and Elizabeth Frazao. 2009. The WIC Program: Background, Trends, and Economic Issues, 2009 Edition. Economic Research Report 73. Alexandria, VA: United States Department of Agriculture, Economic Research Service. 
Oliveira, Victor, Elizabeth Frazao, and David Smallwood. 2010. Rising Infant Formula Costs to the WIC Program: Recent Trends in Rebates and Wholesale Prices. Economic Research Report 93. Alexandria, VA: United States Department of Agriculture, Economic Research Service.

2011. The Infant Formula Market: Consequences of a Change in the WIC Contract Brand. Economic Research Report 124. Alexandria, VA: United States Department of Agriculture, Economic Research Service.

Powell, Lisa M., Sandy Slater, Donka Mirtcheva, Yanjun Bao, and Frank J. Chaloupka. 2007. "Food Store Availability and Neighborhood Characteristics in the United States." Preventive Medicine 44 (3): 189-195.

Rimkus, Leah, Zeynep Isgor, Punam Ohri-Vachaspati, Shannon N. Zenk, Lisa M. Powell, Dianne C. Barker, and Frank J. Chaloupka. 2015. "Disparities in the Availability and Price of Low-Fat and Higher-Fat Milk in U.S. Food Stores by Community Characteristics." Journal of the Academy of Nutrition and Dietetics 115 (12): 1975-1985.

Rossin-Slater, Maya. 2013. "WIC in Your Neighborhood: New Evidence on the Impacts of Geographic Access to Clinics." Journal of Public Economics 102:51-69.

Saez, Emmanuel, Joel Slemrod, and Seth H. Giertz. 2012. "The Elasticity of Taxable Income with Respect to Marginal Tax Rates: A Critical Review." Journal of Economic Literature 50 (1): $3-50$.

Saitone, Tina, Richard Sexton, and Richard Volpe. 2015. "A WICked Problem? Cost Containment in the Women, Infants and Children Program." Applied Economic Perspectives and Policy 37 (3): $378-402$.

Schmalensee, Richard. 1981. "Output and Welfare Implications of Monopolistic Third-Degree Price Discrimination." American Economic Review 71 (1): 242-47.

Stroebel, Johannes, and Joseph Vavra. 2019. "House Prices, Local Demand, and Retail Prices." Journal of Political Economy 127 (3): 1391-1436.

Swann, Christopher. 2007. "Prenatal WIC Participation and Infant Health: Selection and Maternal Fixed Effects." The B.E. Journal of Economic Analysis 6 Policy 7 (1).

Thorn, Betsy, Chrystine Tadler, Nicole Huret, Carole Trippe, Elaine Ayo, Michelle Mendelson, Kelly Lawrence Patlan, Gabriel Schwartz, and Vinh Tran. 2015. WIC Participant and Program Characteristics Final Report, 2014. Technical report. Prepared by Insight Policy Research under Contract No. AG-3198-C-11-0010. Alexandria, VA: United States Department of Agriculture, Food and Nutrition Service. 
United States Department of Agriculture. 2006. WIC Electronic Benefit Transfer (EBT) System Development, Implementation, and Expansion: 5-year Plan (2003-2008). Technical report. Alexandria, VA: USDA, Food and Nutrition Service, Supplemental Food Programs Division, Program Analysis and Monitoring Branch.

. 2007. WIC Food Package Costs and Rebate Summary: Fiscal Year 2005. Technical report. Alexandria, VA: USDA, Food and Nutrition Service, Office of Analysis, Nutrition and Evaluation.

USDA, Food and Nutrition Service. 2019. "Child Nutrition Programs: Income Eligibility Guidelines."

Varian, Hal R. 1985. "Price Discrimination and Social Welfare." The American Economic Review 75 (4): $870-75$.

Vericker, Tracy, Chen Zhen, and Shawn Karns. 2013. Fiscal Year 2010 WIC Food Cost Report. Technical report. Project Officer: Grant Lovellete. Alexandria, VA: United States Department of Agriculture, Food and Nutrition Service, Office of Policy Support.

Waldfogel, Joel. 2007. The Tyranny of the Market: Why You Can't Always Get What You Want. Cambridge, MA: Harvard University Press. 
Figure 1: Effect of EBT on Social Welfare: Market for WIC Benefits.

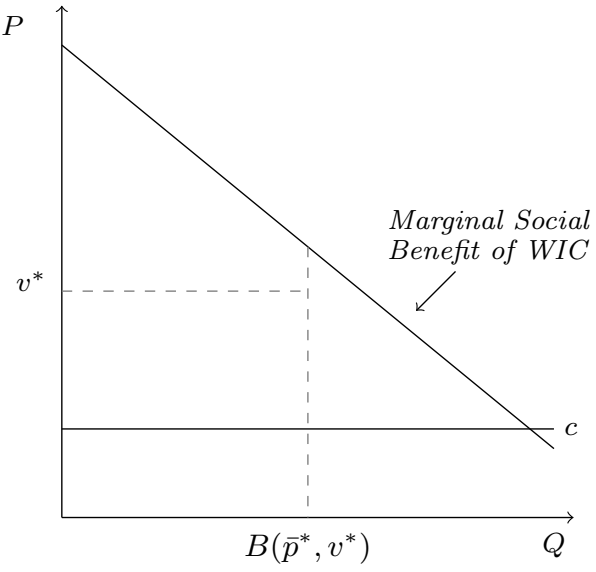

(A) Before EBT: WIC stores distribute a total of $B\left(\bar{p}^{*}, v^{*}\right)$ benefits, where $v^{*}$ is the voucher price and $\bar{p}^{*}$ is the non-WIC price.

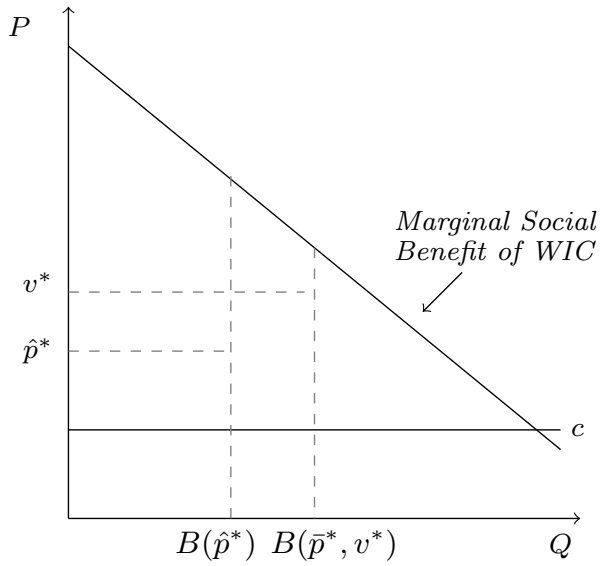

(в) After EBT: Stores charge the pooling price $\hat{p}^{*}$ to WIC and non-WIC customers. WIC profits fall with loss of price discrimination $\rightarrow$ stores leave WIC $\rightarrow$ fewer benefits are distributed: $B\left(\bar{p}^{*}, v^{*}\right) \geq B\left(\hat{p}^{*}\right)$.

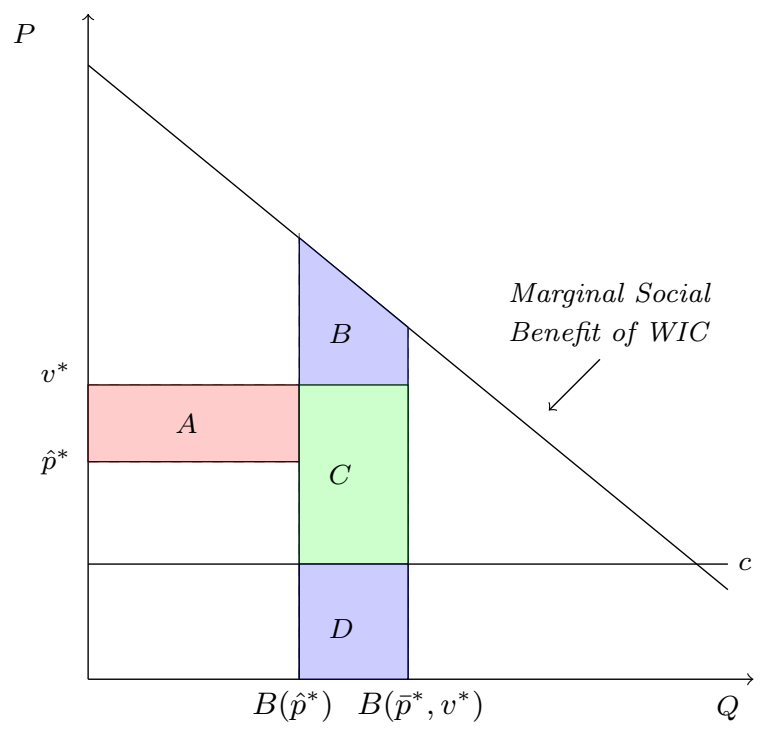

(c) Change in Welfare Associated with EBT

Notes: Please see the text on page 12 for an explanation of each lettered area. 
Figure 2: EBT and Independent WIC Stores per County

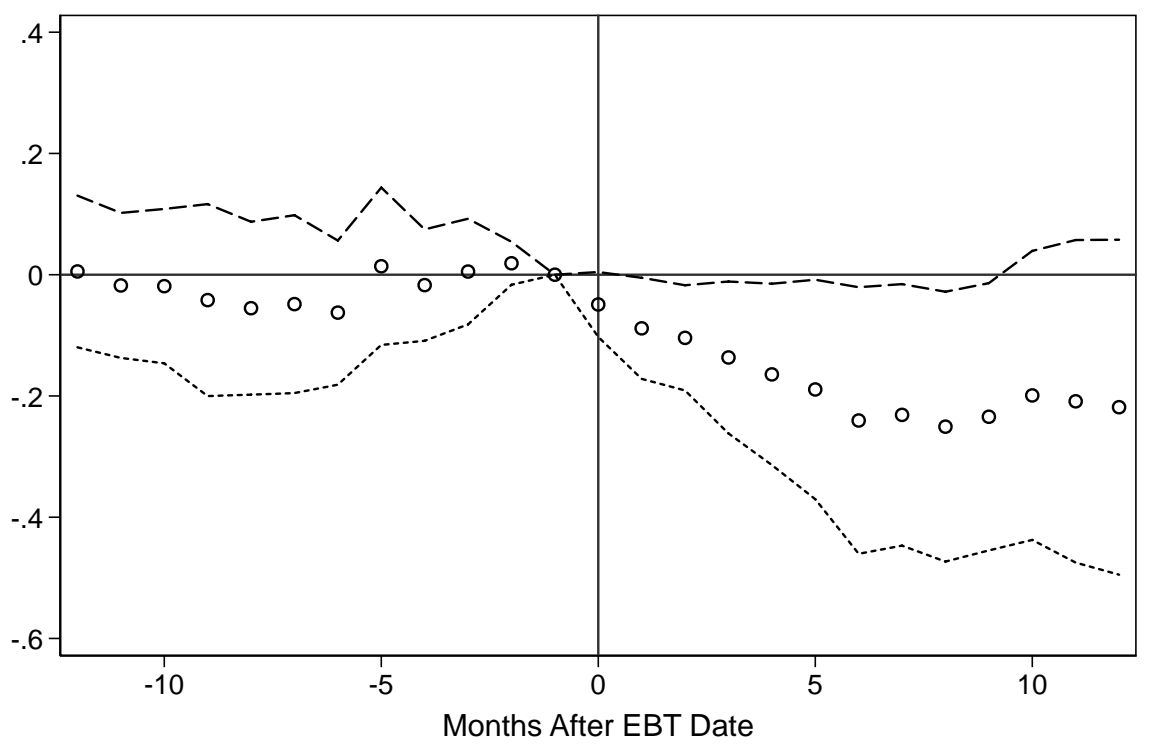

Notes: Please see the notes to Table 2. Plotted are event time coefficients from estimating the event time version of Eq. 3.

Figure 3: EBT and Chain WIC Stores per County

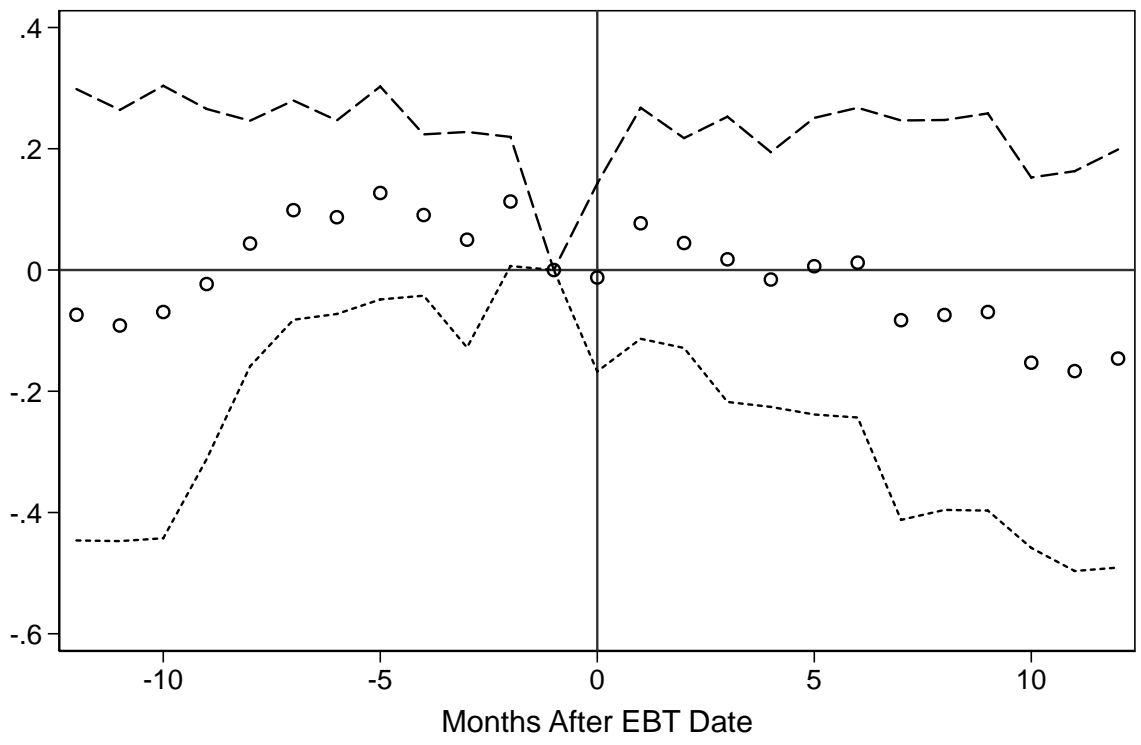

Notes: Please see the notes to Table 2. Plotted are event time coefficients from estimating the event time version of Eq. 3. 
Figure 4: EBT and Likelihood of Exiting WIC, Indep. Stores

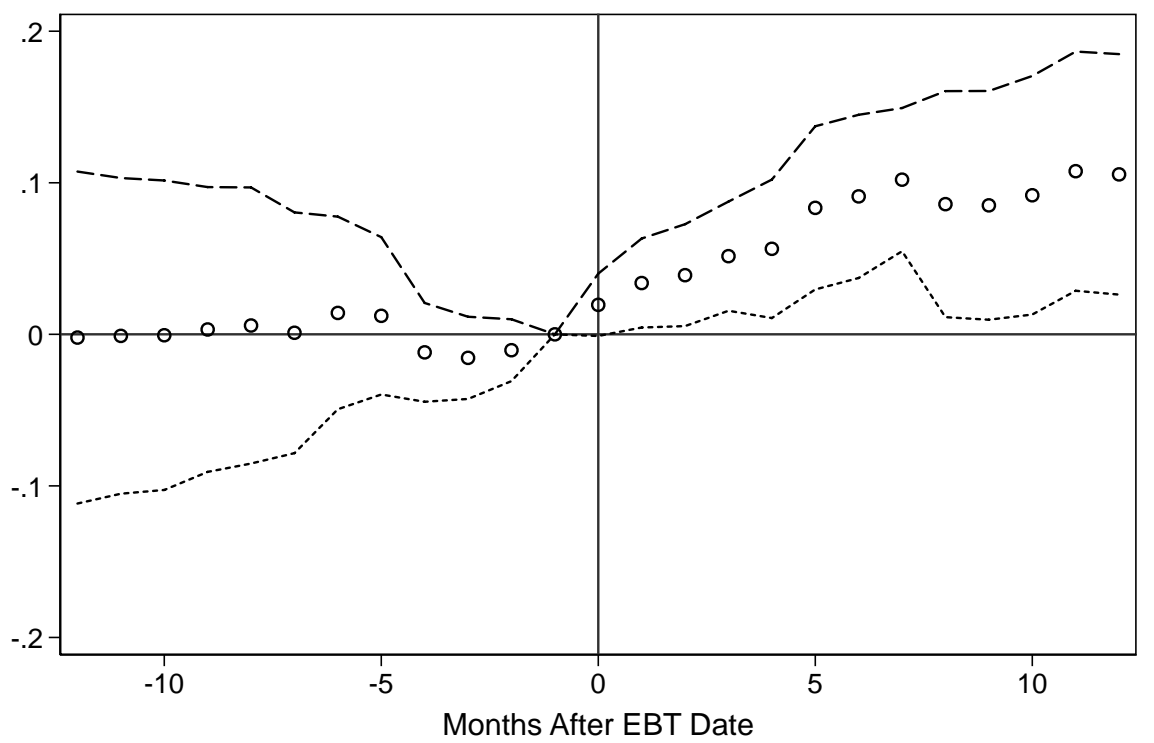

Notes: Please see the notes to Table 3 . Plotted are event time coefficients from estimating the event time version of Eq. 3

Figure 5: EBT and Likelihood of Exiting WIC, Chain Stores

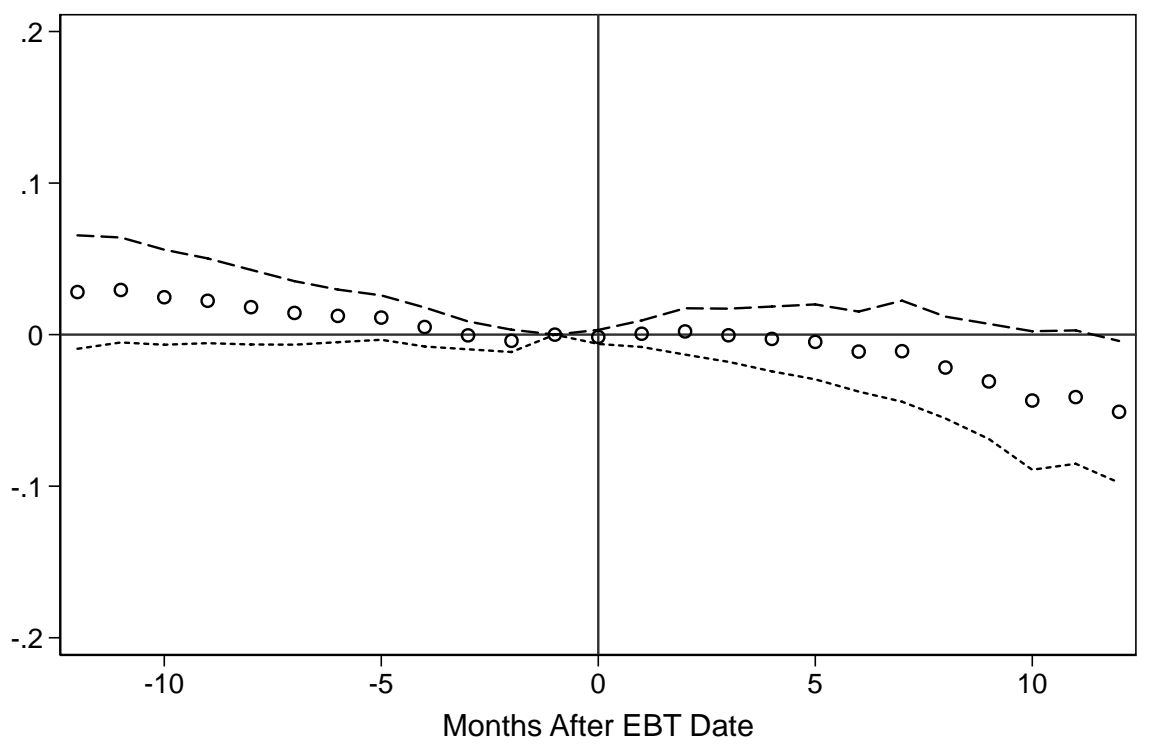

Notes: Please see the notes to Table 3 . Plotted are event time coefficients from estimating the event time version of Eq. 3 
Figure 6: EBT and Prices of WIC Products, Indep. WIC Stores

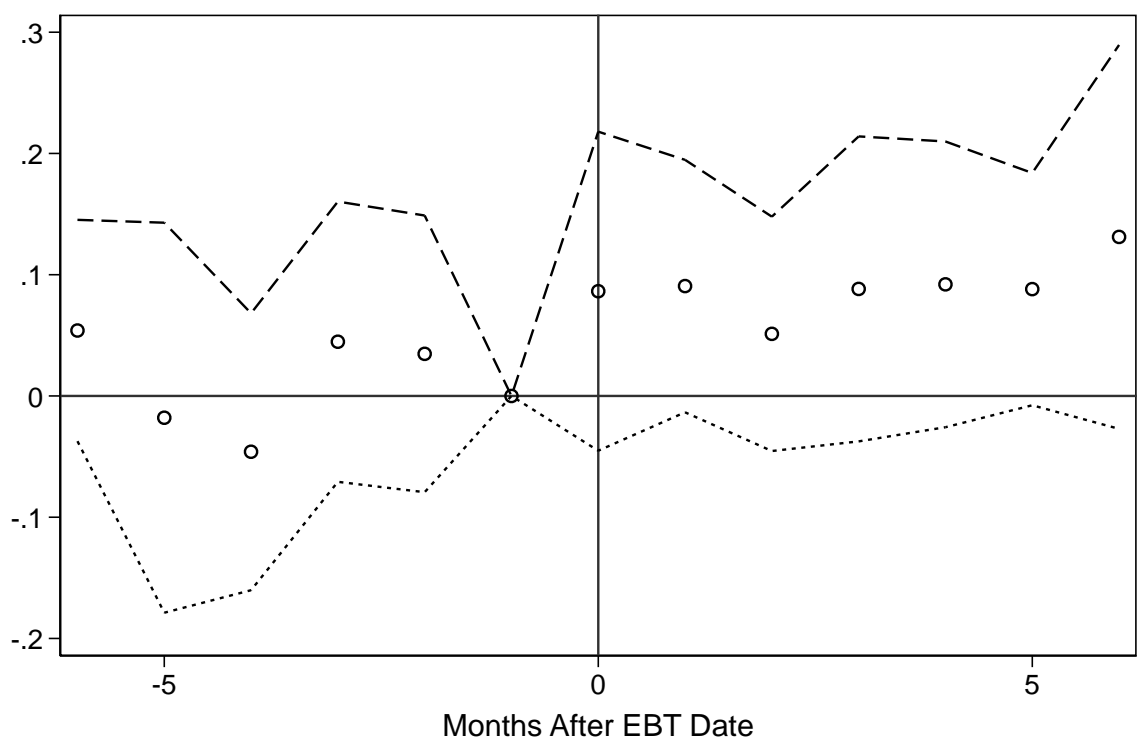

Notes: Please see the notes to Table 4 . Plotted are event time coefficients from estimating the event time version of Eq. 3.

Figure 7: EBT and Prices of WIC Products, Chain WIC Stores

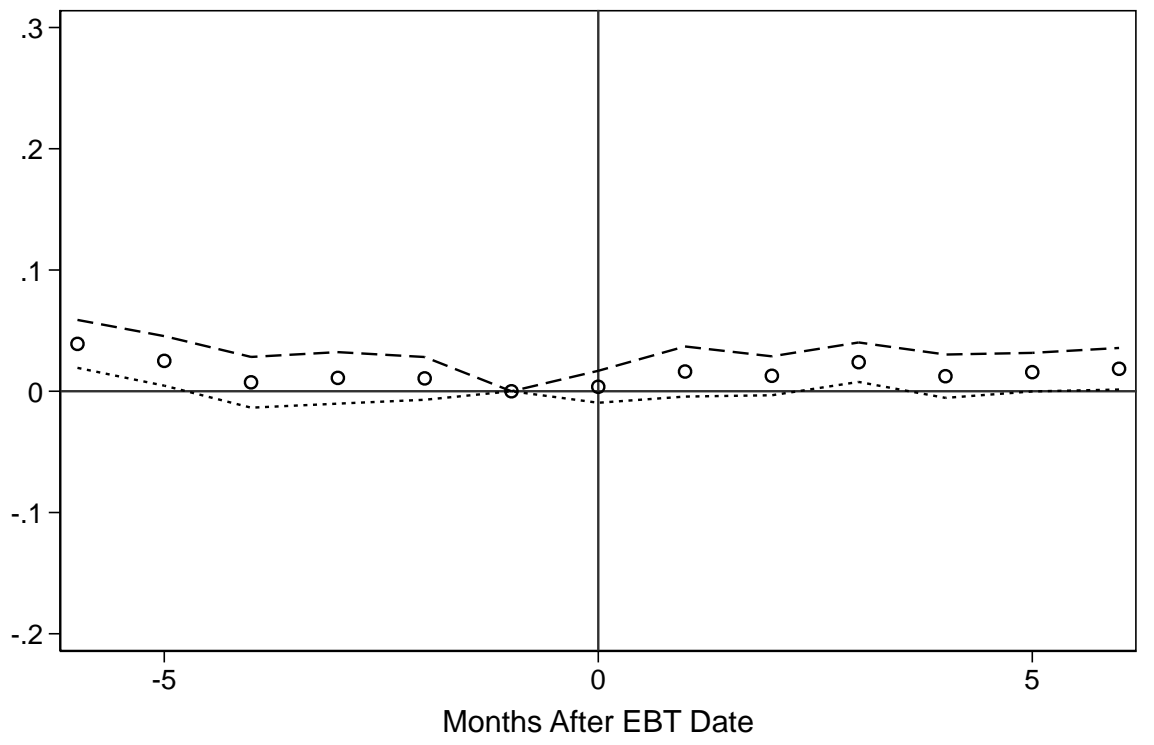

Notes: Please see the notes to Table 4. Plotted are event time coefficients from estimating the event time version of Eq. 3. 
Figure 8: EBT and WIC Births per County

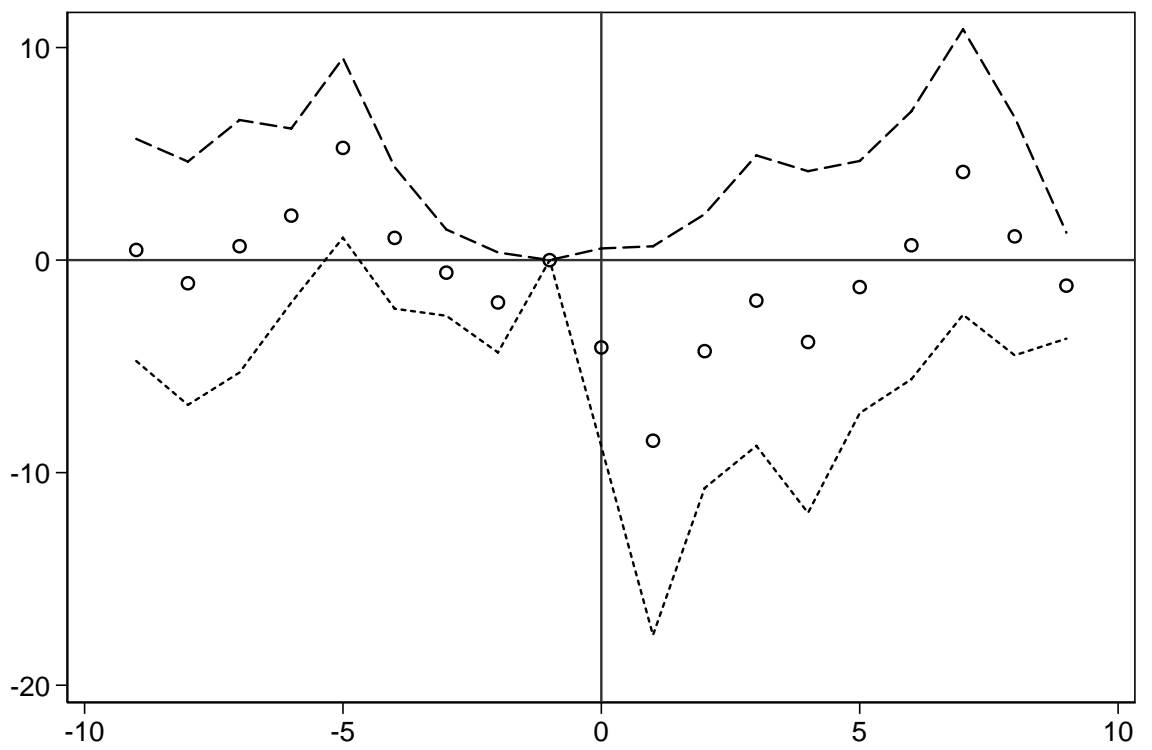

Notes: Please see notes to Table 5. Plotted are event time coefficients from estimating the event time version of Eq. 3.

Figure 9: EBT and High-Poverty WIC Births per County

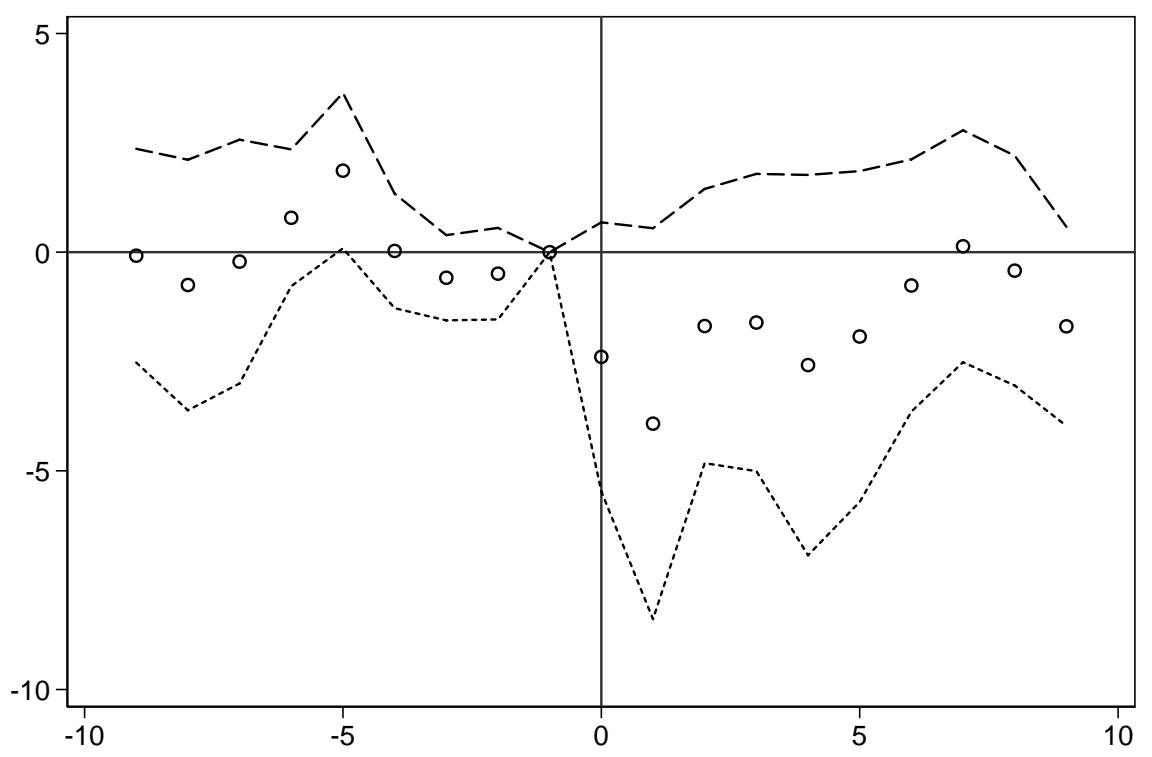

Notes: Please see notes to Table 5. Plotted are event time coefficients from estimating the event time version of Eq. 3 . 
Table 1: Standard Benefit Packages, Texas WIC

\begin{tabular}{|c|c|c|c|c|c|c|c|}
\hline Recipient & Milk & Juice & Eggs & Cheese & Cereal & Legumes & Other \\
\hline $\begin{array}{l}\text { Pregnant and Partially } \\
\text { Breastfeeding Women }\end{array}$ & $5.5 \mathrm{gal}$ & $\begin{array}{l}646 \mathrm{fl} \mathrm{oz} \text { cans or } \\
11.5-12 \text { oz frozen }\end{array}$ & $2 \mathrm{doz}$ & $2 \mathrm{lbs}$ & $36 \mathrm{oz}$ & $\begin{array}{l}118 \mathrm{oz} \text { PB jar } \\
\text { or } 1 \mathrm{lb} \text { beans }\end{array}$ & \\
\hline $\begin{array}{l}\text { Postpartum Women, } \\
\text { Fully Breastfeeding }\end{array}$ & $5.5 \mathrm{gal}$ & $\begin{array}{l}746 \mathrm{fl} \mathrm{oz} \text { cans or } \\
11.5-12 \text { oz frozen }\end{array}$ & $2 \mathrm{doz}$ & $3 \mathrm{lbs}$ & $36 \mathrm{oz}$ & $\begin{array}{l}118 \mathrm{oz} \text { PB jar } \\
\text { or } 1 \mathrm{lb} \text { beans }\end{array}$ & $\begin{array}{l}46 \mathrm{oz} \text { cans tuna and } \\
2 \text { lbs or } 214-16 \text { oz } \\
\text { canned carrots }\end{array}$ \\
\hline $\begin{array}{l}\text { Postpartum Women, } \\
\text { Not Breastfeeding }\end{array}$ & $4.5 \mathrm{gal}$ & $\begin{array}{l}446 \mathrm{fl} \mathrm{oz} \text { cans or } \\
11.5-12 \text { oz frozen }\end{array}$ & $2 \mathrm{doz}$ & $2 \mathrm{lbs}$ & $36 \mathrm{oz}$ & & \\
\hline Infants, 0-11 mos. & & $\begin{array}{l}246 \mathrm{fl} \mathrm{oz} \text { cans or } \\
11.5-12 \mathrm{oz} \text { frozen } \\
(6-11 \text { mos. })\end{array}$ & & & $\begin{array}{l}\text { 16-24 oz, infant } \\
\text { (4-11 mos.) }\end{array}$ & & $\begin{array}{l}\text { Formula, assorted } \\
\text { amounts }\end{array}$ \\
\hline Children, ages 1 to 4 & $4.5 \mathrm{gal}$ & $\begin{array}{l}446 \mathrm{fl} \mathrm{oz} \text { cans or } \\
11.5-12 \text { oz frozen }\end{array}$ & $2 \mathrm{doz}$ & $2 \mathrm{lbs}$ & $36 \mathrm{oz}$ & $\begin{array}{l}118 \text { oz PB jar } \\
\text { or } 1 \mathrm{lb} \text { beans }\end{array}$ & \\
\hline
\end{tabular}

Notes: This table lists the standard monthly benefit packages for individuals enrolled in Texas WIC during fiscal years 2007 to 2009. Participants can choose to substitute 1 gallon of milk (at most) for four cans of evaporated milk. Children under the age of 2 are not given peanut butter, so always receive $1 \mathrm{lb}$ of beans. Source: Food Package Code and Description Guide from Fiscal Years 2007-2009. The guide for FY 2007 is accessible here: http://web.archive.org/web/20070628001335/http: //www.dshs.state.tx.us/wichd/nut/pdf/FoodPkgCode_DescGuide.pdf.

Table 2: Effect of EBT on Total WIC Stores by County

\begin{tabular}{ccc}
\hline & $\frac{\text { Independent }}{(1)}$ & $\frac{\text { Chain }}{(2)}$ \\
\cline { 2 - 3 } & $-0.1095^{* *}$ & -0.0642 \\
After EBT & $(0.0508)$ & $(0.0894)$ \\
\hline N & 11,424 & 11,424 \\
Mean, Dep. Var. & 1.0253 & 7.7014 \\
\hline
\end{tabular}

\begin{tabular}{l|l|l|l|}
\hline Notes: Each column reports the results of a separate regression estimating Eq. 3 & The sample is drawn from administrative
\end{tabular} data on WIC vendors in Texas during fiscal years 2007 to 2010. Excluded from the sample are WIC-only stores, Above 50 stores, pharmacies, and military commissaries. Units of observation are county-year-month cells and the outcome is total chain or independent stores per cell. All regressions include year-month fixed effects, county fixed effects, and county group-specific linear time trends. Standard errors are clustered at the county level. + indicates $p<0.10$; ** indicates $p<0.05$; *** indicates $p<0.01$ 
Table 3: Effect of EBT on Likelihood a Store Exits WIC

\begin{tabular}{rccccc}
\hline & \multicolumn{2}{c}{ Independent } & & \multicolumn{2}{c}{ Chain } \\
\cline { 2 - 3 } \cline { 5 - 5 } & $(1)$ & $(2)$ & & $(3)$ & $(4)$ \\
\hline After EBT=1 & $0.0537^{* *}$ & 0.0141 & & -0.0026 & $-0.0439^{* *}$ \\
& $(0.0252)$ & $(0.0416)$ & & $(0.0115)$ & $(0.0175)$ \\
After EBT $=1 \times$ ZIP & & 0.1744 & & $0.2341^{* *}$ \\
Poverty & & $(0.1701)$ & & $(0.0962)$ \\
\hline N & 18,382 & 18,334 & 104,497 & 104,497 \\
Mean, Dep. Var. & 0.3695 & 0.3698 & 0.1591 & 0.1591 \\
\hline
\end{tabular}

Notes: Each column reports the results of a separate regression estimating Eq. 3. Please see the notes to Table|2 for information on the source of data. The sample is an unbalanced panel of WIC stores, with one observation for each month from FY 2007 to FY 2010 that occurs on or after a store's first month of participation in WIC. The outcome is an indicator for whether the store exits or has previously exited WIC in a given month. If the WIC store participates in the last month of FY 2010 (9/2010), the outcome variable is never equal to 1. "ZIP Poverty" is the share of households living in poverty in the store's ZIP code (Census Bureau 2011b). All regressions include year-month fixed effects, store fixed effects, and county group-specific linear time trends. Standard errors are clustered at the county level. + indicates $p<0.10 ; * *$ indicates $p<0.05 ; * * *$ indicates $p<0.01$

Table 4: Effect of EBT on Prices of WIC Foods in WIC Stores

(1)

Independent WIC Stores
(2)

Chain WIC Stores

$(0.0313)$
0.0010

$(0.0066)$

\begin{tabular}{ccc}
\hline After EBT & $0.0644^{* *}$ & 0.0010 \\
& $(0.0313)$ & $(0.0066)$ \\
\hline $\mathrm{N}$ & 1,745 & 94,106
\end{tabular}

Notes: Each column reports results from a separate regression estimating Eq. 3. The sample is drawn from the Nielsen Consumer Panel and is limited to purchases of WIC-eligible products at WIC stores made by households residing in Texas from FY 2007 to FY 2009. WIC-eligible products are identified using the rules in A.1. Whether a store participated in WIC is proxied using an indicator for whether there was at least one WIC store of a given size (chain, single outlet) in the ZIP code of residence of the panelist shopper in the year of the purchase. Section 5.2 provides further detail. The outcome is log price per unit and is net of any discounts received at the point of sale. All regressions include year-month fixed effects, store fixed effects, UPC fixed effects, and county group-specific linear time trends. Standard errors are clustered at the county level. + indicates $p<0.10 ; * *$ indicates $p<0.05 ; * * *$ indicates $p<0.01$ 
Table 5: Effect of EBT on WIC Participation

(1)

(3)

(4)

WIC Births WIC Births High Poverty WIC Births High Poverty WIC Births

Born after EBT $-3.8563^{* *}$

(1.7398)

Born 0-9 Months after EBT

$-3.9151^{* *}$

$-2.1681^{+}$

$(1.2410)$

Born 10+ Months after EBT
$-2.1380^{+}$

$-2.4900^{* *}$

(1.2604)

14,167

27.4343

Mean, Dep. Var. $74.8541 \quad 74.8541$

14,167

27.4343

$(1.2863)$

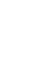

Notes: Each column reports results from a separate regression estimating Eq. 3. The sample is drawn from the universe of birth
. The certificates from the state of Texas for the years 2005 to 2009. The sample excludes cases in which the mother resided outside of Texas or in a county without an EBT date. Also excluded are births with missing values of WIC participation or gestation length. Units of observation are birth year-birth month-county cells and the outcome is total WIC births or total high-poverty WIC births per cell. "Born After EBT" indicates the date of birth is after the county's EBT roll-out date. "Born 10+ Months After EBT" indicates that the month of birth is $\geq 10$ months after the date of EBT rollout. "Born 0-9 Months after EBT" indicates that the month of birth is $\geq 0$ and $\leq 9$ months after the date of EBT rollout. All regressions include year-month fixed effects, county fixed effects, and county group-specific linear time trends. Standard errors are clustered at the level of mother's county of residence. + indicates $p<0.10$; ${ }^{* *}$ indicates $p<0.05$; *** indicates $p<0.01$ 